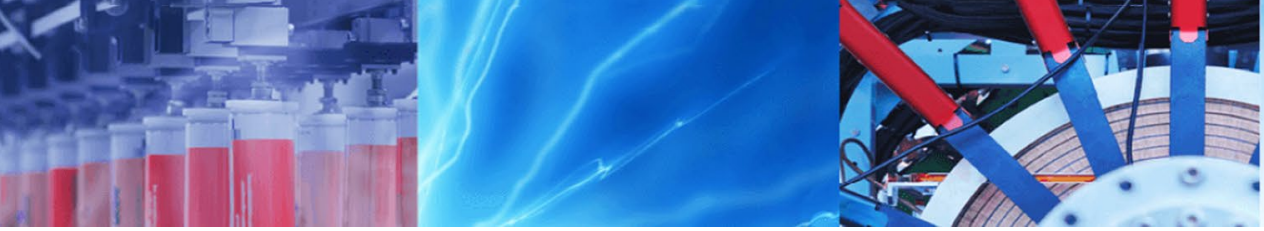

Research Article

\title{
Evaluation of surface shortwave and longwave downwelling radiations over the global tropical oceans
}

\author{
Venugopal Thandlam ${ }^{1,2}$ D Hasibur Rahaman ${ }^{2}$
}

C The Author(s) 2019 OPEN

\begin{abstract}
In the present study, daily downwelling shortwave $\left(Q_{S}\right)$ and longwave radiation $\left(Q_{L}\right)$ data from one satellite and two hybrid products have been evaluated using Global Tropical Moored Buoy Array during 2001-2009 in the tropical oceans. Daily satellite data are used from the Clouds and Earth's Radiant Energy System (CERES) program. Data are obtained using Moderate Resolution Imaging Spectroradiometer (MODIS) (CM) aboard the Terra and Aqua satellites. Coordinated Ocean Research Experiments (CORE-II) and Tropical Flux data (TropFlux) are the other two hybrid products used in this study. The analysis shows that majority of $\mathrm{Q}_{S}$ observations as well as derived products lie in $200-300 \mathrm{Wm}^{-2}$ range in all the three tropical oceans. Both $Q_{S}$ and $Q_{L}$ in all products overestimated the majority of the observations. Yet, they underestimated the lower $\left(0-100 \mathrm{Wm}^{-2}\right)$ values in $Q_{S}$ and higher $\left(300-440 \mathrm{Wm}^{-2}\right)$ values in $Q_{L}$. Majority of the $Q_{L}$ observations lie within $390-420 \mathrm{Wm}^{-2}$ range, and CM slightly overestimated this observed distribution in the Pacific and the Atlantic Oceans. But, majority of the observations in the Indian Ocean lie within $420-450 \mathrm{Wm}^{-2}$ range. This implies that the tropical Indian Ocean receives $30 \mathrm{Wm}^{-2}$ more energy as compared to the tropical Pacific and the Atlantic in the form of downwelling longwave radiation. Daily observed $Q_{S}$ shows dominant seasonal cycle over the central, the eastern Pacific and the eastern Atlantic. On the other hand, the western Pacific, the central Atlantic and the Indian Oceans show intraseasonal variations. All products show this variation with high root-mean-square error (RMSE) values $\left(Q_{S}\right.$ and $\left.Q_{L}\right)$ over the Indian Ocean than in the Pacific and the Atlantic Oceans. Downwelling radiation from CORE-II shows highest RMSE (for both $Q_{S}$ and $Q_{L}$ ) with least correlation coefficient (CC), and TropFlux has lowest RMSE and highest CC among all products in all three tropical oceans. CM has intermediate values of standard deviation, CC and RMSE. These results are not seasonally dependent, since the seasonal statistics are consistent with seasonal changes. Assuming that the SST is only driven by the downwelling shortwave and longwave fluxes, the errors associated with monthly SST can be as large as $0.2-0.3$ $(0.1-0.2){ }^{\circ} \mathrm{C}$ associated with errors in $Q_{S}\left(Q_{L}\right)$. Both $Q_{S}$ and $Q_{L}$ in CORE-II have lower spatial variability as compared to other datasets. $Q_{L}$ in the tropical oceans shows seasonal spatial variability determined by intertropical convergence zone positions. This variability does not change significantly over the Pacific and the Atlantic Oceans. The summer and winter monsoon patterns in the Indian Ocean guide the $Q_{L}$ variability. Opposite to $Q_{S}$, higher $Q_{L}$ values have lower variability. Thus, this study aims at finding better radiation dataset to use in the numerical models and deduce that satellite data could be an alternative to existing reanalysis products.
\end{abstract}

Keywords Downwelling shortwave radiation - Downwelling longwave radiation - CERES - MODIS - RMSE - Standard deviation · GTMBA · CORE-II - TropFlux

Electronic supplementary material The online version of this article (https://doi.org/10.1007/s42452-019-1172-2) contains supplementary material, which is available to authorized users.

$\triangle$ Venugopal Thandlam, venux4@gmail.com | ${ }^{1}$ Department of Earth Sciences, Uppsala University, Uppsala, Sweden. ${ }^{2}$ Indian National Centre for Ocean Information Services (INCOIS), Ministry of Earth Sciences (MoES), Hyderabad, India.

SN Applied Sciences (2019) 1:1171 | https://doi.org/10.1007/s42452-019-1172-2

Received: 27 May 2019 / Accepted: 27 August 2019 / Published online: 6 September 2019 


\section{Introduction}

The atmosphere and ocean interact and respond through the exchange of mass, momentum and heat fluxes. Heat flux variability is a major contributor to weather and climate on different timescales. Shortwave radiation and latent heat flux are the principal contributors of heat flux variability in the tropics [48]. Tropical oceans receive high solar irradiance in the form of shortwave radiation. Subtropics and Polar Regions receive relatively less solar irradiance. The excess heat received over the tropical ocean balances through turbulent mixing, longwave radiation, and transport to the higher latitudes through ocean circulation [107]. Tropical and subtropical cyclones also contribute to the large energy transfer from the ocean to atmosphere, mainly through the release of latent heat on weekly time scales [59]. Heat fluxes modulate the intraseasonal oscillations (ISO) in the tropical oceans $[35,103,111]$. Heat fluxes are also a major modulator of large-scale climatic events like El Niño/Southern Oscillation, Indian Ocean Dipole, Atlantic Meridional Mode [33, 66, 112, 113, 117, 126].

The net heat flux at the sea surface is the sum of net radiative and turbulent fluxes $[16,19,70,73]$. Radiative flux has two components, i.e., longwave and shortwave. The downwelling fluxes of shortwave and longwave radiation, together with other meteorological variables, are used to force the ocean general circulation models (OGCMs). The near-surface atmospheric state is used to parameterize the surface boundary conditions for the heat and momentum flux [52] in the OGCMs. Parekh et al. [67] highlighted the potential impact of accurate momentum forcing on the seasonal SST variations over the north Indian Ocean. Similarly, the heat balance in the boundary conditions prescribed for the OGCMs is limited by uncertainties in turbulent and radiative heat fluxes ([110] and the references therein). These limitations in the forcing fields are partially responsible for the OGCMs to cause bias in simulating intraseasonal, seasonal, interannual variability and climatic features [64]. Hence, accurate near-surface atmospheric fields are essential for the accurate simulations in a forced ocean model. Rahaman and Ravichandran [81] have evaluated the near-surface air temperature and humidity from Coordinated Ocean Research Experiments (CORE-II), Objectively analized air-sea fluxes (OAFLUX), and Tropical Flux (TropFlux) in the Indian Ocean to find a better dataset to use in the model forcing.

The forced ocean model simulation accuracy also depends on the accuracy of the downwelling radiative fluxes. There are many forcing fields available over the global ocean such as DRAKKAR from European Community [9], JRA-do [109] and most commonly used
Common Reference Ocean-Ice Experiments (COREII) dataset to run global ocean and sea ice model [52, 53]. All these datasets are based on corrected reanalysis products. In addition to these reanalysis products, satellite-derived products such as International Satellite Cloud Climatology Project (ISCCP-FD), Clouds and the Earth's Radiant Energy System (CERES), etc., are also a source of radiative flux data. Trolliet et al. [108] compared the irradiance data from reanalysis product such as MERRA- 2 and ERA- 5 and three satellite-derived datasets (HelioClim 3v5, SARAH 2 and CAMS) with five PIRATA buoys during 2012-2013. This study concluded that present existing reanalysis data have large biases, errors and poor correlation coefficient values compared to the independent in situ buoy observations. However, the performances are similar between the three satellitederived datasets used in this study.

Chaudhuri et al. [12] compared the various atmospheric reanalysis surface products over global ocean with ISCCP data to estimate the uncertainties in air-sea boundary forcing. Interim ECMWF Re-Analysis (ERAlnterim), COREII, 25-Year Japanese Reanalysis Project (JRA-25), and NCEP-NCAR are evaluated against satellite-derived observations for eight different fields in this study. No product was compared well in all fields with satellite-derived observations, both in time mean and in time variable analysis. Reanalysis products are mostly comparable to each other due to their assimilation of common observations and their similar physical assumptions. Evaluation of the surface radiation fluxes with buoy observations in the Southeastern Pacific Ocean during 2000-2012 [75] and at the Pacific "Cold Tongue" of the Tropical Pacific Ocean concluded that satellite data match well with the observations which is followed by reanalysis data than the model data $[72,74]$. Pinker et al. [70, 73] compared the heat budgets derived at the ocean-atmosphere interface from satellites and blended products, with in situ observations in the Atlantic during 2003-2005. Ramesh Kumar et al. [83] used satellite data (MODIS) as the reference to evaluate the radiative fluxes from Ocean Moored Network for the Northern Indian Ocean (OMNI). A study from Ma and Pinker [60] concluded that the Earth Radiation Balance from satellite observations has large bias over ocean than their better agreement over land. These differences are further attributed to frequent changes in satellite observing systems, degradation of sensors, restricted spectral intervals, viewing geometry of sensors, and changes in the quality of atmospheric inputs that drive the inference schemes.

Feng et al. [20, 21] generated high accuracy daily photosynthetically active radiation (PAR, solar radiation at $400-700 \mathrm{~nm}$ ) by evaluating several radiative transfer and artificial intelligence models with ground observations at twenty-nine stations over China. Wenmin Qin et al. 
[78] compared the performances of four shortwave solar radiation models in different climates over China and concluded that the cloud fraction and solar zenith angle are the major parameters influencing the model accuracies. A similar study from Feng et al. [20, 21] using 15 typical empirical models concluded that the model with secondorder polynomial performed better than other models for estimating diffuse radiation in different climate zones over China. Zou et al. [132] studied the spatial distribution and long-term variation in global solar energy based on the Coupled Model Intercomparison Project Phase 5 (CMIP5) and found that the global mean surface solar radiation significantly decreased in 1850-2005. Wang et al. [119] compared various models for predicting diffuse solar radiation in China using daily observations at 17 stations during 1993-2015 to highlight the accuracy of newly proposed models compared with empirical models.

Raschke et al. [86] used ISCCP data to show the effect of clouds on the radiation fields. It shows that the ISCCP data underestimate the absorption of solar radiation in the tropical and subtropical atmosphere about 10 to 20 $\mathrm{Wm}^{-2}$ on seasonal to annual time scale. Recent satellitebased monthly CERES estimates of incident solar radiation agree better with the surface measurements rather than at daily timescales. These monthly estimates are also useful to capture the seasonal variation of incident solar radiation [123]. Differences between the FLASHFlux, CERES shortwave radiation flux, and surface measurements are larger in cloudy-sky conditions than in clear-sky conditions over Loess Plateau [127]. Kato et al. [42] estimated the bias (RMSE) between computed and observed monthly mean irradiances with ten years of CERES data as, 4.7 (13.3) $\mathrm{Wm}^{-2}$ for $Q_{S}$ and -2.5 (7.1) $\mathrm{Wm}^{-2}$ for $Q_{L}$ over global oceans. Rutan et al. [91] compared CERES surface radiantion fluxes data with 85 globally distributed land (37) and ocean buoy (48) surface observations as well as several other publicly available global surface radiantion flux data products. This study finds that the downward fluxes from CERES have the monthly bias (standard deviation) of $3.0 \mathrm{Wm}^{-2}(5.7 \%) Q_{S}$ and $-4.0 \mathrm{Wm}^{-2}$ (2.9\%) for $Q_{\mathrm{L}}$ compared to surface observations. Also, the standard deviation between surface downward shortwave flux calculations and observations at the 3-hourly time scale was reduced during the diurnal cycle of cloud changes. Improvement is smaller for $Q_{L}$ due to an additional sensitivity to boundary layer temperature/ humidity, which has a weaker diurnal cycle compared to clouds. Complete technical details and the present status of CERES can be found from Barkstrom [4] and Smith et al. [101].

The other blended flux products like OAFlux [128] and TropFlux [77] combine the desirable aspects of observations, satellite products, and model analysis. But, these blended products have limitations, in having complete set of data for model forcing (e.g., OAFlux) or in their global coverage (e.g., TropFlux). ISCCP-FD is not available for the recent decade (from 2009) and is used in all these datasets for the radiative fluxes at the sea surface. The ISCCP data have problems over oceans, in particular, over the Atlantic Ocean [60, 70, 73]. There are a few studies which evaluated radiative fluxes from different satellite, reanalysis and models with the observations over land and ocean [70-75]. But all these studies either contain only single downwelling radiation parameter/dataset or confined to a narrow region for a short period of time. In the present work, we try to fill this gap by evaluating both the components of downwelling radiation (shortwave and longwave) from CERES, CORE-II and TropFlux data derived from ISCCP in the tropical oceans.

To the best of our knowledge, no long-term evaluation studies are available for the radiative fluxes from different datasets with in situ observations, in all the three tropical oceans. Hence, in this study, we evaluated the radiative components from satellite and reanalysis products with in situ observations over global tropical oceans. Though the similar attempt was made by Pinker et al. [71], the study includes surface shortwave radiation from single (satellite) product only for a short duration (2003-2005). Hence, the objective of the present study is to undertake a comparison of the downwelling fluxes of radiation from the existing and commonly used radiation forcing fields and satellite data over the tropical oceans with in situ observations. In addition, we tried to assess whether satellite data can be complementary to the reanalysis data in forcing the OGCMs. The radiation data from a satellite-based product, the Moderate Resolution Imaging Spectrometer (MODIS) from the Clouds and Earth's Radiant Energy System (CERES) (CM), and two blended products, CORE-II and TropFlux, are evaluated with independent in situ observations over the tropical oceans. It is worth to mention that this study is first of its kind to evaluate various radiation datasets in all three tropical oceans for a longer period (about a decade). Since CORE-II and TropFlux use ISCCP data, essentially, we evaluated the ISCCP radiation datasets with all available in situ radiation data for a decade in the global tropical ocean which was never attempted before.

This paper organized as follows. Section 2 describes the various references and hybrid datasets used in this study. In Sect. 3.1, we discussed the spatial variability of hybrid datasets. We illustrated the details and results of the validation process with reference data from Global Tropical Moored Buoy Array (GTMBA) [61] in Sect. 3.2. In Sect. 3.3, we presented the error in SST due to error in hybrid and reanalysis data. The main conclusions and summary are in Sect. 4. 


\section{Data and methodology}

This study makes use of the GTMBA radiation data to evaluate downwelling shortwave radiation $\left(Q_{S}\right)$ and downwelling longwave radiation $\left(Q_{L}\right)$ fluxes from various sources in the global tropical oceans. The near real time or regularly updating satellite/hybrid products are used for evaluation. Various flux data sources and their spatial and temporal resolution details are given in Table 1. These products are selected based on their frequent use in the GCMs by modeling community to force the numerical models. The comparisons of these products are made with GTMBA collocated and concurrent datasets with nearest grid point data. We used datasets with spatial grid resolutions of $1^{\circ}$ and $1.9^{\circ}$ and compared with collocated buoy observations. This approximation does not give much differences in our results. Trolliet et al. [108] showed the comparison of point location with gridded data is valid over tropical ocean since no strong systematic gradient in irradiance present over short distance in the tropical ocean. The mean, standard deviation (SD) and root-meansquare error (RMSE) are computed with the Eqs. 1, 2 and 3. The following sections concisely present each of the datasets used in the present study.

Mean/Average $A=\frac{1}{n} \times \sum_{i}^{n} x_{i}$

where $A$ is average (or arithmetic mean), $n$ is the total number of observations, and $x_{i}$ is the daily value of each observation in the list of observations averaged.

$\mathrm{SD}=\sqrt{\frac{1}{n} \sum_{i=1}^{n}\left(x_{i}-\mu\right)^{2}}$

where $x_{i}$ is an individual value, $\mu$ is the mean/expected value, and $n$ is the total number of daily observations

RMSE $=\sqrt{\frac{\sum_{i=1}^{n}\left(\hat{y}_{i}-y_{i}\right)^{2}}{n}}$

Table 1 The spatial and temporal details of reanalysis data used in the study

\begin{tabular}{lccll}
\hline Data product & Start date & \multicolumn{2}{c}{ Resolution } & \multirow{2}{*}{ End date } \\
\cline { 3 - 4 } & & Spatial & Temporal & \\
\hline CM & $01 / 01 / 2001$ & $1^{\circ} \times 1^{\circ}$ & Daily & $31 / 12 / 2009$ \\
CORE-II & $01 / 01 / 2001$ & $1.9^{\circ} \times 1.9^{\circ}$ & Daily & $31 / 12 / 2009$ \\
TropFlux & $01 / 01 / 2001$ & $1^{\circ} \times 1^{\circ}$ & Daily & $31 / 12 / 2009$ \\
\hline
\end{tabular}

where $y_{i}$ is the observed value for the ith observation, $\hat{y}_{i}$ is the estimated value, and $n$ is the total number of daily observations.

\subsection{Global Tropical Moored Buoy Array}

Moored buoy observing system in all three tropical oceans (GTMBA) is a multinational effort to get surface meteorological and subsurface oceanic near-real-time data for research and applications. It has three components, namely Tropical Atmosphere Ocean/Triangle Trans-Ocean Buoy Network (TAO/TRITON) in the tropical Pacific Ocean [62], Pilot Research Moored Array in the Tropical Atlantic (PIRATA) in the tropical Atlantic Ocean [8] and Research Moored Array for African-Asian-Australian Monsoon Analysis and Prediction (RAMA) in the tropical Indian Ocean [63]. The GTMBA data undergo rigorous quality control procedures before delivering to users, to ensure high accuracy standards $[23,24,51,65,69]$. Quality control is performed in three stages, i.e., daily, weekly and monthly (https://www.pmel.noaa.gov/gtmba/data-quali ty-control). Complete details of the GTMBA project/program are discussed in McPhaden et al. [61] and Venugopal et al. [110] and the references therein. The uncertainty in the shortwave radiation is $2 \%$ due to drift criteria. Foltz et al. [22] reported monthly mean accumulation biases as large as $-200 \mathrm{Wm}^{-2}$ and record-length mean biases of -10 $\mathrm{Wm}^{-2}$ in the shortwave radiation from the moorings in the Atlantic (PIRATA) due to dust accumulation.

All mooring locations data for downwelling shortwave radiation and downwelling longwave radiation are used during the study period. However, many buoy locations have data gaps and there exist a few stations with only either $Q_{S}$ or $Q_{L}$. In the Indian Ocean among 27 mooring sites, $Q_{L}$ is available only at $0^{\circ} \mathrm{N}, 80.5^{\circ} \mathrm{E} ; 15^{\circ} \mathrm{N}, 90^{\circ} \mathrm{E}$ and $8^{\circ} \mathrm{S}$, $67^{\circ} \mathrm{E}$ (three locations) during the study period. $Q_{S}$ data are available at 19 sites in the Indian Ocean. Among the seven stations delivering $Q_{L}$ in the Atlantic Ocean, only four locations have the data in the study period. However, $Q_{S}$ has data over 17 out of 21 locations. Relatively, Pacific Ocean has more moorings, and data availability is better than other oceans. The $Q_{L}$ data delivered from 11 moorings and $Q_{S}$ data obtained from 32 out of 34 sites in the Pacific Ocean are used in the study.

Figure 1 shows the distribution of GTMBA data in all three tropical oceans. Locations of the GTMBA buoys can be found in supplementary figure $\mathrm{S} 1$. The Pacific Ocean has more data points for both $Q_{S}$ and $Q_{L}$, followed by the Atlantic and the Indian Oceans. Daily $Q_{S}$ and $Q_{L}$ data with quality flags of one and two (highest or default quality) are chosen to evaluate reanalysis/hybrid/satellite products. Data availability period of all mooring sites is not same. Nonetheless, all available data during 2001-2009

SN Applied Sciences 
Fig. 1 Frequency distribution of a downwelling shortwave $\left(\mathrm{Wm}^{-2}\right)$ and $\mathbf{b}$ downwelling longwave $\left(\mathrm{Wm}^{-2}\right)$ from all GTMBA observations used to collocate with the concurrent data from CM, CORE-II and TropFlux
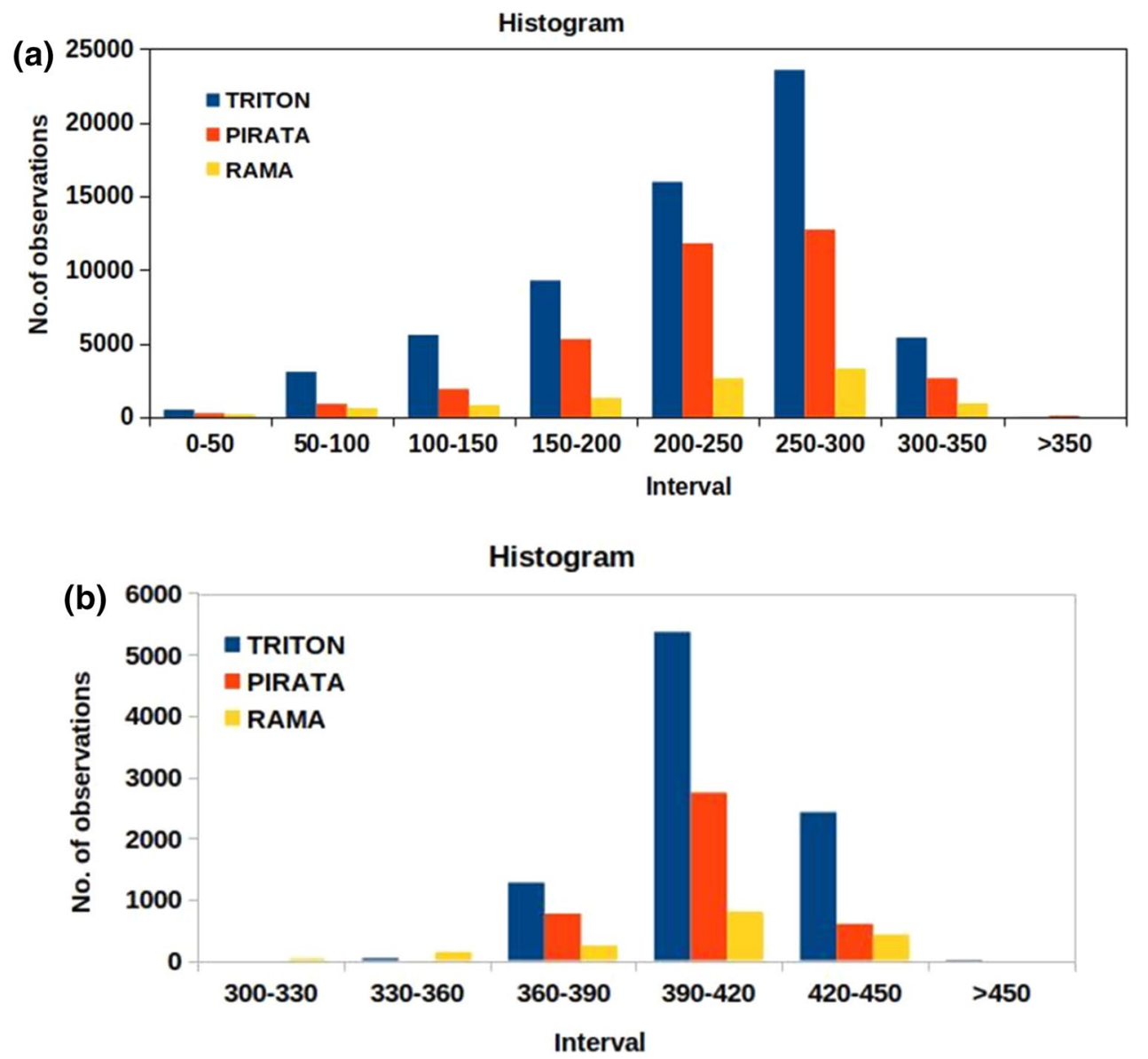

are considered in the present study. Data gaps and spuriousness of mooring data are paid attention while performing validation of reanalysis products. Sharp peaks and dips $\left(>50 \mathrm{Wm}^{-2}\right)$ in the daily PIRATA data over a few locations are removed in the process of evaluation. We reported the GTMBA program office about these spurious values and subsequently our inputs were used to correct the GTMBA data base (personal communication).

\subsection{CERES/MODIS (CM)}

The CERES project as a successor to Earth Radiation Budget Experiment (ERBE) has been providing radiative flux components from 2000 to till date $[6,43,122]$. CERES program focused on measuring outgoing longwave radiation (OLR) radiances and reflected solar radiances to an accuracy of $1 \%$ and $2 \%$, respectively. The ERBE $[5,6]$ program provided significant information about the energetics and the effects of clouds in modulating the energy balance [31, 82]. The CERES project conceived as a successor to ERBE to compile a data record for the investigation of interannual variations of climate [31, 43, 122]. In the present study, we have used daily averaged CM observed Geostationary enhanced, temporally interpolated surface radiative fluxes for all-sky conditions (version 3) data of $Q_{S}$ and $Q_{L}$. The computed fluxes produced using the Langley Fu-Liou radiative transfer model. The CERES Synoptic (SYN1 deg), edition 3, product provides climate-quality global 3-hourly $1^{\circ} \times 1^{\circ}$ gridded top of atmosphere, in-atmosphere, and surface radiant fluxes available from March 2000 to February 2017 [110]. However, we have used data during 2001-2009 in the current analysis to match the data period of other reanalysis/hybrid products. Details of the product computation, methodology and validation of CM data are given in Rutan et al. [91].

\subsection{CORE-II}

The CORE data combine NCAR/NCEP reanalysis with satellite data, by certain limitations of reanalysis [52]. Although there are many cautions, the CORE datasets and CORE protocol provide a means for the global ocean climate modeling community to integrate ocean-ice models without a fully coupled atmospheric General Circulation Model (GCM) [29]. However, these data have known biases and were therefore adjusted based on comparisons with observations [102]. Details of the correction methods are available in the work of Large and Yeager [52]. The interannual forcing fields are 
available until 2009 due to unavailability of observed radiative flux data. This CORE-II was produced using corrected NCEP2 data [37] and ISCCP radiation data [129]. Since the ISCCP data are available until 2009, CORE-II forcing fields are not available beyond 2009. Hence, present study contains the daily averaged corrected interannual forcing version 2 data during 2001-2009. The spatial resolution of the data is in $1.9^{\circ} \times 1.9^{\circ}$ grid size.

\subsection{TropFlux}

The TropFlux data provide daily air-sea heat and momentum fluxes over the tropical oceans $\left(30^{\circ} \mathrm{N}-30^{\circ} \mathrm{S}\right)$. TropFlux uses bias, amplitude corrected ERA-I ( $10 \mathrm{~m}$ winds, $2 \mathrm{~m}$ air and sea temperature, $2 \mathrm{~m}$ air relative humidity and downward radiative fluxes), and ISCCP (shortwave radiation) fluxes. All bias corrections to the ISCCP data are based on the GTMBA data and are described in detail in Kumar et al. [50]. Additional details on the ISCCP datasets, its methodology and evaluation can be found in Rossow and Schiffer [90], and Schiffer and Rossow [93]. Evaluations with mooring data (GTMBA) have shown that TropFlux is more accurate than the other reanalysis products [50]. Since TropFlux provides net shortwave and longwave radiation data, we compute $Q_{S}$ and $Q_{L}$ fluxes given by Eqs. 3 and $4[52,77]$.

The net solar flux $\left(Q_{N S}\right)$ from the incident solar insolation $Q_{S}$ on the ocean surface; the solar albedo, $\alpha=0.05$ [88], and the downwelling longwave flux from the atmosphere, $Q_{L}$, is given by:

$Q_{\mathrm{NS}}=Q_{\mathrm{S}}(1-\alpha)$

The longwave radiation occurs from the ocean surface provided by the blackbody radiation law which is a function of $\varepsilon \sigma(\mathrm{SST})^{4}$, where $\sigma=5.679 \times 10^{-8} \mathrm{Wm}^{-2}$ per $\mathrm{K}^{4}$, which is the Stefan-Boltzmann constant and $\varepsilon$ is the surface emissivity, considered to be 1.0 [58]. The net longwave flux becomes

$Q_{\mathrm{NL}}=Q_{\mathrm{L}}-\sigma(\mathrm{SST})^{4}$

\section{Results and discussions}

\subsection{Spatial variability of $Q_{S}$ and $Q_{L}$ in the global tropical oceans}

\subsubsection{Seasonal mean distribution of $Q_{S}$}

The tropical Indian and the western Pacific Ocean together constitute the major part of the large warm pool on the Earth [85]. The air-sea interaction and their fluxes over this region play a significant role in shaping climate on regional and global scales [96]. Although a few previous studies reported the annual distribution of $Q_{S}$ during El Niño and La Niña $[68,124]$, its seasonal spatial distribution has not been studied in those studies except during El Niño and La Niña time. Hence, in addition to evaluate the different products with GTMBA in situ data, we show the seasonal spatial distributions of $Q_{S}$ in all these hybrid datasets. In this section, we show the spatial distribution of $Q_{S}$ and $Q_{L}$ seasonal mean and daily variability over tropical oceans. Figure 2 shows the seasonal mean $Q_{S}$ over global tropical oceans from CM, CORE-II and TropFlux. $Q_{S}$ shows high values over the subtropical region (between 10 and 30 degree of latitude band not in the equator region) in all seasons. This is mainly due to the low cloudiness over these subtropical regions rather than equator, where the total cloudiness values are $~ 60-70 \%$ due to the intertropical convergence zone (ITCZ) [68]. The reason being explained by Pavlakis et al. [68], entire southern hemisphere receives uniform high $Q_{S}$ during DJF with an average value of $300-340 \mathrm{Wm}^{-2}$. These high $Q_{S}$ values are subject to shift in the thermal equator towards southern hemisphere coupled with the presence of less clouds. Thus, this region well exposed to receive more $Q_{S}$ during this season. The south pacific convergence zone (SPCZ) and the eastern equatorial Indian Ocean show low $Q_{S}$ values $\left(\sim 200 \mathrm{Wm}^{-2}\right)$. The equatorial Pacific and Atlantic Oceans also have values less than $300 \mathrm{Wm}^{-2}$. These low values correspond to the presence of ITCZ and associated convection over equator and SPCZ. Hatzianastassiou et al. [32] have shown a strong anti-correlation between $Q_{S}$ and cloud amount. Hence, the lower $Q_{S}$ values are associated with the regions with high convections and cloud cover such as ITCZ. The low band of $Q_{S}$ over the equatorial Pacific Ocean lies above the equator and almost stationary throughout the year [2]. In the Indian Ocean, the low $Q_{S}$ values extend till $25^{\circ} \mathrm{N}$ associated with the northward shift of ITCZ during the Indian Summer Monsoon [26, 28, 120] (Fig. 2). Variability is large over the low $Q_{S}$ region and is evident from the seasonal SD plots (Fig. 3). Entire northern hemisphere has low $Q_{S}$ values $\left(\sim 130-180 \mathrm{Wm}^{-2}\right)$ in the north of equator till $30^{\circ} \mathrm{N}$ during DJF. This is due to the low solar radiation reaching this region during this season. Both CM and CORE-II show similar mean spatial distribution pattern. TropFlux shows low $Q_{S}$ values over the northern Pacific and Atlantic Oceans as compared to CM and CORE-II. This bias could be attributed to the bias in the radiation data used in the TropFlux and the correction applied to generate this product [50]. But the variability is less in CORE-II as compared to other two products (Fig. 3).

The equator shows large $Q_{S}$ during spring. Except in the northern ITCZ, the west coast of north America and SPCZ locations have low $Q_{S}$ values $\left(\sim 200-220 \mathrm{Wm}^{-2}\right)[40,44$, 87] (Fig. 2). Similar spatial pattern of spring prevails with extent of low $Q_{S}$ values over the north Indian Ocean during summer is associated with the Indian summer monsoon [1, $7,15]$. TropFlux in summer shows different spatial patterns 


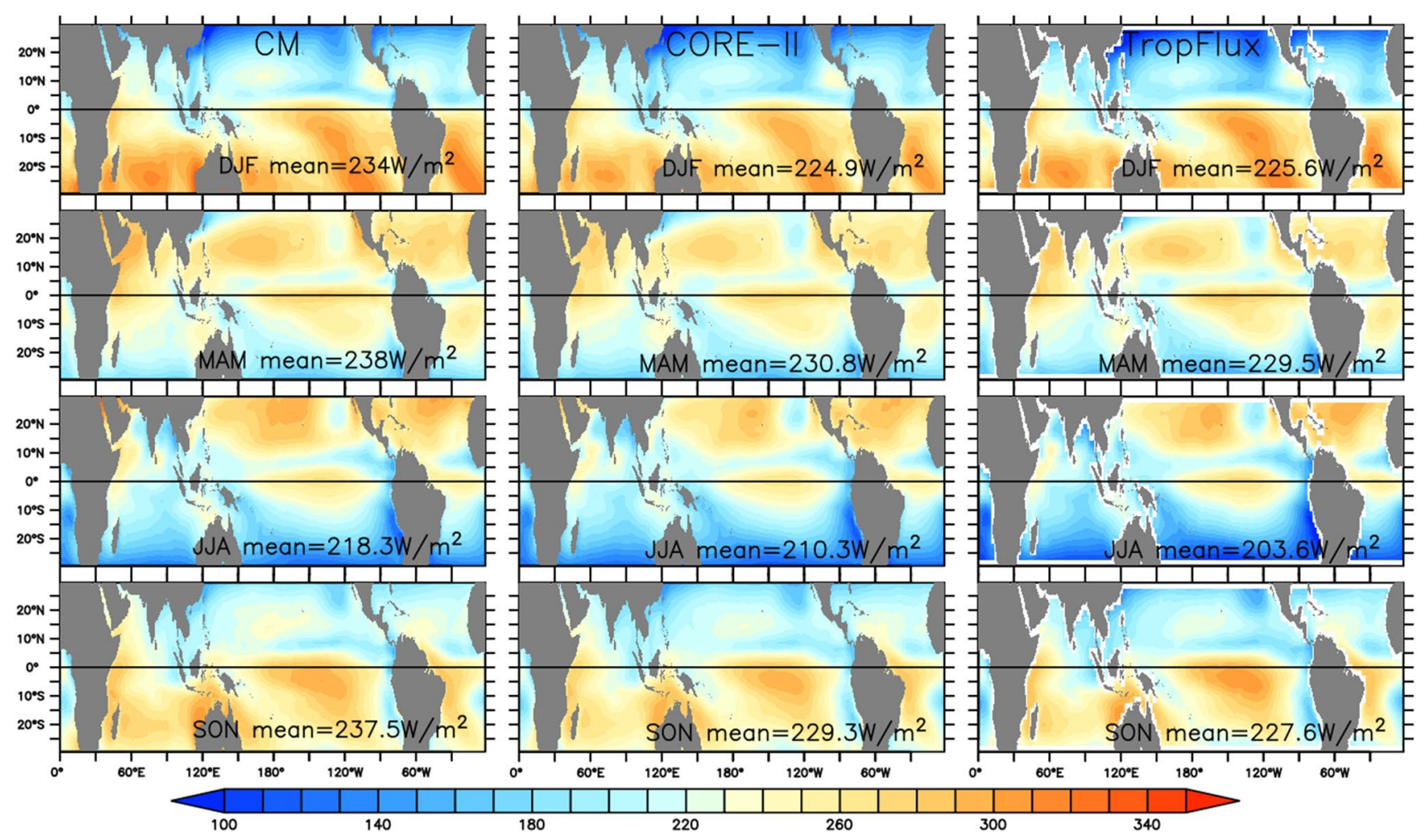

Fig. 2 Seasonal mean of downwelling shortwave radiation $\left(\mathrm{Wm}^{-2}\right)$ from $\mathrm{CM}, \mathrm{CORE}-\mathrm{II}$, and TropFlux in the global tropical oceans. Basin-averaged mean values are given in each sub panel

as in winter, as compared to CORE-II and CM (Fig. 2). All products show low values in the subtropics $\left(20^{\circ}-30^{\circ} \mathrm{S}\right.$ latitude band). The $Q_{S}$ values over the west coast of the South America and Africa show much lower values as compared to the adjacent regions of the same latitudes. TropFlux shows lowest values over these regions as compared to the other products. Hatzianastassiou et al. [32] have shown that these lower values are due to the large cloud amounts ( 80\%) present over these regions. The $Q_{S}$ in JJA over the Indian Ocean shows low values as compared to the Pacific and Atlantic Oceans. It is due to the presence of clouds, especially low-level stratus and stratocumulus forms during the Indian summer monsoon [12, 32]. The western Indian Ocean and the east coast of African/Somali show large $Q_{S}$ in all seasons. This is mainly due to the absence of clouds over the western Indian Ocean throughout the year $[26,27,121]$. Low $Q_{S}$ values (less than $100 \mathrm{Wm}^{-2}$ ) are observed during DJF in the north of $20^{\circ} \mathrm{N}$ and during JJA in the south of $20^{\circ} \mathrm{S}$. All the reanalysis products show similar spatial and temporal patterns with a change in the magnitude. The equatorial belt and the Indonesian Through Flow regions are consistently receiving low $Q_{S}$ values with magnitude below $200 \mathrm{Wm}^{-2}$. This region hosts the large warm pool. The presence of warm waters with strong convection and deep cloud formation that are opaque to $Q_{S}$ would lead to low $Q_{S}$. CM shows the highest mean values in all seasons among all the products, followed by CORE-II. Large $Q_{S}$ values over the subtropical Pacific, Atlantic and the western Indian Oceans are associated with subsidence regions due to the presence of anti-cyclonic conditions over these regions [32]. Daily variability between seasons has no significant change and has similar regional mean values (Fig. 3). CORE-Il variability is low in all seasons as compared to CM and TropFlux. This can be seen in Tables 2, 3 and 4.

\subsubsection{Seasonal mean distribution of $Q_{\mathrm{L}}$}

Figure 4 shows the seasonal mean of $Q_{L}$ from CM, CORE-II and TropFlux in global tropical oceans for different seasons (DJF, MAM, JJA and SON). Unlike $Q_{S}, Q_{L}$ in the tropical oceans shows the spatial pattern determined by ITCZ positions. Large $Q_{L}$ values are seen over ITCZ. But, except in the Indian Ocean, seasonal patterns and magnitudes of $Q_{L}$ do not change significantly over the tropical oceans. The spatial pattern of $Q_{L}$ changes with the summer and winter monsoon over the Southeast Asia [55]. All the reanalysis products in the north Indian Ocean have low $Q_{L}$ during DJF which corresponds to shift in the thermal equator leading to changes in the amount 


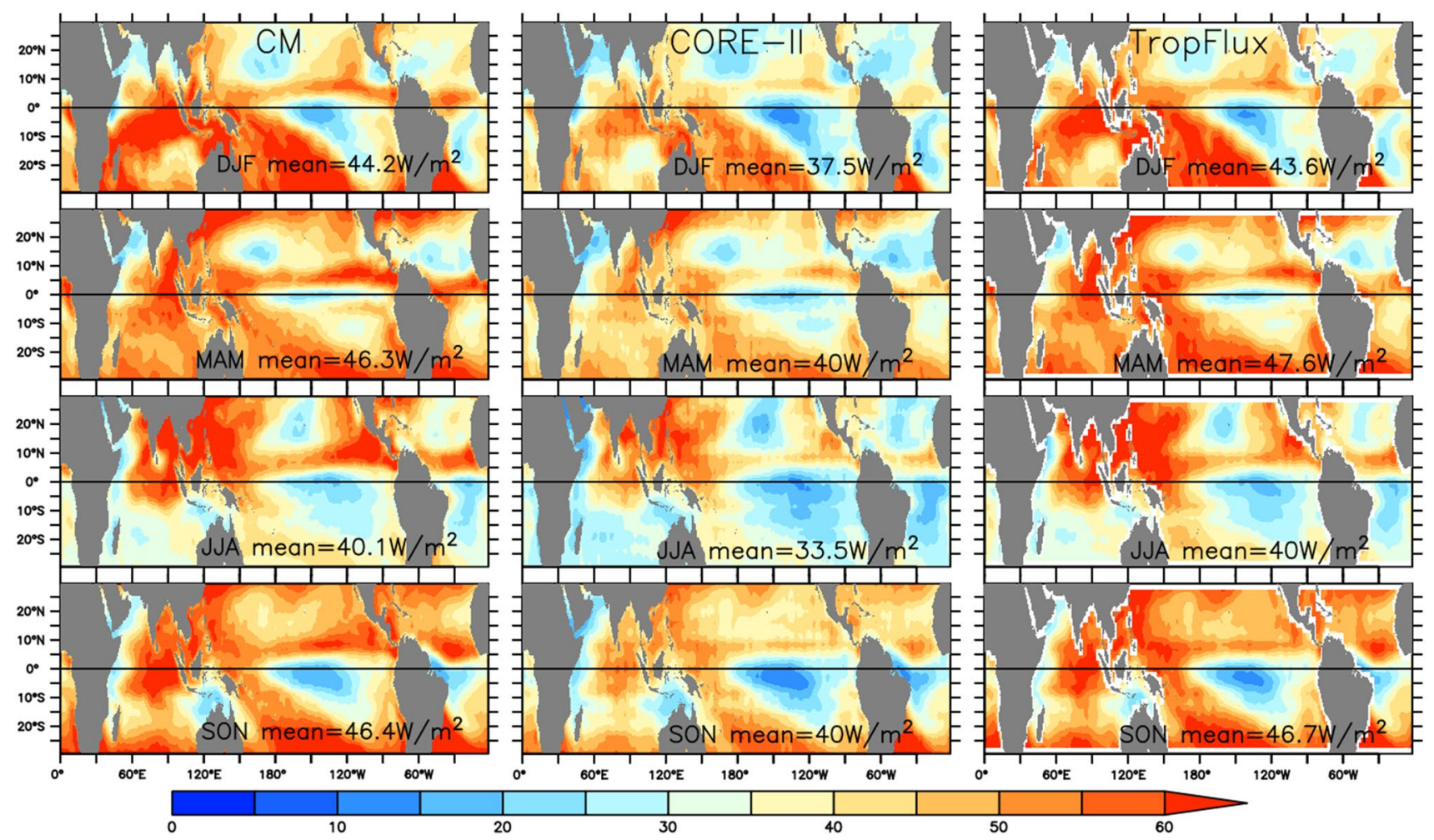

Fig. 3 Seasonal SD of downwelling shortwave radiation $\left(\mathrm{Wm}^{-2}\right)$ from CM, CORE-II, and TropFlux in the global tropical oceans. Basin-averaged SD values are given in each sub panel

Table 2 Statistics of downwelling shortwave radiation $\left(Q_{S}\right)$ and downwelling longwave radiation $\left(Q_{L}\right)$ of all reanalysis/satellite products compared with TRITON data in the Pacific Ocean during 2001-2009

Table 3 Statistics of downwelling shortwave radiation $\left(Q_{S}\right)$ and downwelling longwave radiation $\left(Q_{L}\right)$ of all reanalysis/satellite products compared with PIRATA data in the Atlantic Ocean during 2001-2009
$Q_{S}\left(\right.$ mean $=227.27 \mathrm{Wm}^{-2}, \mathrm{SD}=65 \mathrm{Wm}^{-2}$ )

Number of collocated data points: 63,309

\begin{tabular}{lrrrrrrr}
\hline Parameter & \multicolumn{1}{c}{ CM } & CORE-II & TropFlux & & CM & CORE-II & TropFlux \\
\hline Bias $\left(\mathrm{Wm}^{-2}\right)$ & 7.23 & -0.22 & -4.62 & & -3.68 & -0.20 & 3.33 \\
SD $\left(\mathrm{Wm}^{-2}\right)$ & 47.12 & 45.53 & 58.83 & & 13.92 & 16.77 & 16.77 \\
RMSE $\left(\mathrm{Wm}^{-2}\right)$ & 40.41 & 43.60 & 36.58 & & 8.78 & 11.94 & 10.56 \\
Mean $\left(\mathrm{Wm}^{-2}\right)$ & 234.50 & 227.05 & 222.65 & & 404.48 & 407.96 & 411.48 \\
CC & 0.79 & 0.74 & 0.83 & & 0.89 & 0.75 & 0.82 \\
\hline
\end{tabular}

$Q_{\mathrm{L}}\left(\right.$ mean $=408.15 \mathrm{Wm}^{-2}, \mathrm{SD}=17.02$ $\mathrm{Wm}^{-2}$ )

Number of collocated data points: 9106
$Q_{\mathrm{S}}\left(\right.$ mean $\left.=232.70 \mathrm{Wm}^{-2}, \mathrm{SD}=56.58 \mathrm{Wm}^{-2}\right)$ Number of collocated data points: 35,604

\begin{tabular}{lrrrrrrr}
\hline Parameter & \multicolumn{1}{c}{ CM } & CORE-II & TropFlux & & CM & CORE-II & TropFlux \\
\hline Bias $\left(\mathrm{Wm}^{-2}\right)$ & 5.00 & 2.22 & -0.45 & -3.76 & -1.12 & 0.89 \\
SD $\left(\mathrm{Wm}^{-2}\right)$ & 42.51 & 39.92 & 51.04 & & 14.50 & 19.05 & 18.40 \\
RMSE $\left(\mathrm{Wm}^{-2}\right)$ & 34.88 & 39.63 & 32.21 & & 9.27 & 13.59 & 14.46 \\
Mean $\left(\mathrm{Wm}^{-2}\right)$ & 237.70 & 234.92 & 232.24 & & 400.40 & 403.04 & 405.04 \\
CC & 0.79 & 0.72 & 0.83 & & 0.83 & 0.71 & 0.64 \\
\hline
\end{tabular}

$Q_{\mathrm{L}}\left(\right.$ mean $=404.16 \mathrm{Wm}^{-2}, \mathrm{SD}=14.80$ $\mathrm{Wm}^{-2}$ )

Number of collocated data points: Number 
Table 4 Statistics of downwelling shortwave radiation $\left(Q_{S}\right)$ and downwelling longwave radiation $\left(Q_{L}\right)$ from all reanalysis products compared with RAMA data in the Indian Ocean

\begin{tabular}{|c|c|c|c|c|c|c|}
\hline \multicolumn{4}{|c|}{$\begin{array}{l}Q_{S}\left(\text { mean }=223.67 \mathrm{Wm}^{-2}, \mathrm{SD}=70.182 \mathrm{Wm}^{-2}\right) \\
\text { Number of collocated data points: } 9789\end{array}$} & \multicolumn{3}{|c|}{$\begin{array}{l}Q_{\mathrm{L}}\left(\text { mean }=417.78 \mathrm{Wm}^{-2}, \mathrm{SD}=18.45 \mathrm{Wm}^{-2}\right) \\
\text { Number of collocated data points: } 1639\end{array}$} \\
\hline Parameter & CM & CORE-II & TropFlux & $\mathrm{CM}$ & CORE-II & TropFlux \\
\hline $\operatorname{Bias}\left(\mathrm{Wm}^{-2}\right)$ & 3.51 & -2.75 & -9.1 & -6.63 & -7.99 & 3.58 \\
\hline $\mathrm{SD}\left(\mathrm{Wm}^{-2}\right)$ & 52.37 & 48.23 & 60.62 & 17.23 & 23.38 & 21.66 \\
\hline RMSE $\left(\mathrm{Wm}^{-2}\right)$ & 43.16 & 50.58 & 40.46 & 9.17 & 13.7 & 9.55 \\
\hline Mean $\left(\mathrm{Wm}^{-2}\right)$ & 227.18 & 220.92 & 214.57 & 411.15 & 409.79 & 421.36 \\
\hline CC & 0.79 & 0.69 & 0.83 & 0.94 & 0.89 & 0.92 \\
\hline
\end{tabular}

of downward radiation receiving at the surface. The low $Q_{L}$ region in the Pacific and Atlantic Oceans shifted to north of $20^{\circ} \mathrm{N}$ during DJF due to less radiation over these regions in the northern winter. High $Q_{\mathrm{L}}$ values greater than $400 \mathrm{Wm}^{-2}$ are observed in JJA over the Indian Ocean. These high $Q_{L}$ values in the Pacific and Atlantic Oceans are limited to the equatorial belt extended up to $10^{\circ}$ north and south. CM has the least global mean in all seasons, followed by CORE-II, and TropFlux with the highest mean value. Peak values of $Q_{L}$ are concentrated at the equatorial belt and over the Indonesian Through Flow region during all seasons. Low (high) variability corresponds to the high (low) mean of $Q_{L}$ (Fig. 5). Entire tropical belt (10 S-10 N), including the Indo-Pacific warm pool region, shows lowest variability in all seasons and in all three reanalysis products due to the persistent cloud and rainfall over this region. CORE-II shows maximum $S D$ values both in the north and southern hemispheres independent of seasons, followed by TropFlux and CM.

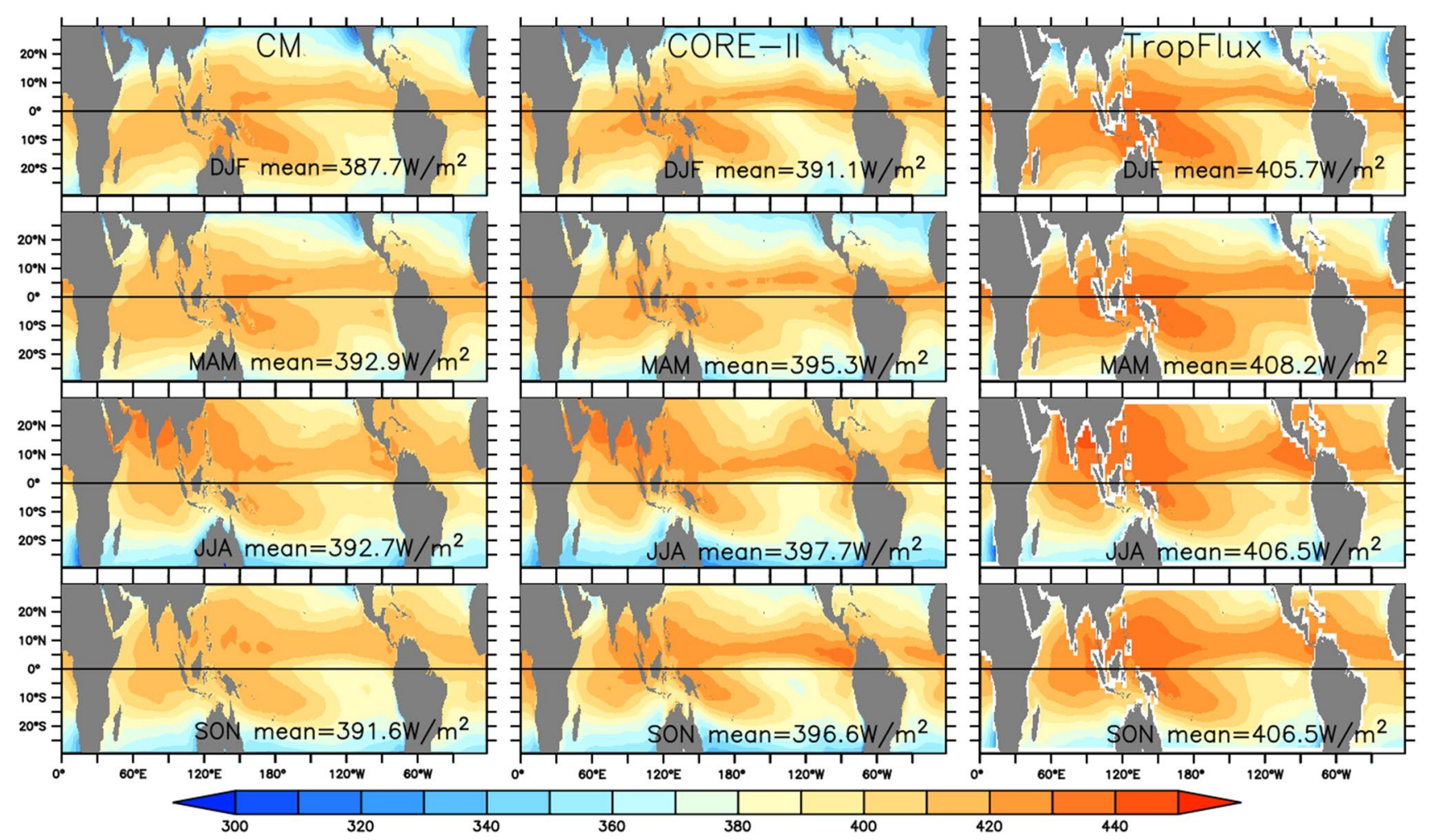

Fig. 4 Seasonal mean of downwelling longwave radiation $\left(\mathrm{Wm}^{-2}\right)$ from $\mathrm{CM}, \mathrm{CORE}-\mathrm{II}$, and TropFlux in the global tropical oceans. Basin-averaged mean values are given in each sub panel 


\subsection{Temporal variation of $Q_{S}$ and $Q_{L}$ in the global tropical oceans}

\subsubsection{Pacific Ocean}

The distribution of $Q_{S}$ and $Q_{L}$ from in situ observations (TRITON), CM, CORE-II, and TropFlux is shown in Fig. 6a. Majority of $Q_{S}$ observations as well as derived products lie in $200-300 \mathrm{Wm}^{-2}$ range (Fig. 6a). All products overestimated the observed $Q_{S}$ in the $200-250 \mathrm{Wm}^{-2}$ range and underestimated the low $\left(100-150 \mathrm{Wm}^{-2}\right)$ and high $\left(300-350 \mathrm{Wm}^{-2}\right)$ values. $Q_{S}$ from CORE-II has no match with the observations in the $300-350 \mathrm{Wm}^{-2}$ range. Other products performed better to meet the observations in this range (Fig. 6a). This discrepancy in matching the different ranges with the observations could be due to errors in the radiative transfer algorithms and biases in the input data used to develop the products. The downward energy flux $\left(Q_{L}\right)$ at the ocean surface in the tropical Pacific Ocean mostly lies in the $390-420 \mathrm{Wm}^{-2}$ range (Fig. 6b). All products have this near Gaussian distribution pattern. Both CORE-II and TropFlux data have better match with observations. But TropFlux has higher values in the $420-450 \mathrm{Wm}^{-2}$ range. This result is noticeable as the TropFlux use the GTMBA observations for the calibration and bias corrections. All products are in good agreement with observations at $360-390 \mathrm{Wm}^{-2}$ range. However, $Q_{L}$ from CM failed to capture the values in the $420-450 \mathrm{Wm}^{-2}$ range (Fig. 6a). Thus, CM has large bias in the higher $Q_{L}$ range. Comparison with the magnitude does not offer any physical insights to know why the differences exist. But, it is more revealing when mean diurnal cycle or irradiance sorted by meteorological conditions is compared. This kind of study requires more focus into regional and remote forcing factors in each of the three tropical oceans and on each product evaluated. However, present study focusses only on evaluating and validating the existing reanalysis and hybrid products to find the best alternative to use in model forcing.

Figure 7 shows the daily time series of $Q_{S}$ from $C M$, CORE-II, TropFlux, and observations from TRITON buoy for a few locations over the western (Figs. 7a, b), the central (Fig. 7c) and the eastern Pacific Oceans (Fig. 7d) during 2001-2009. Mean and standard deviation $\left(\mathrm{Wm}^{-2}\right)$ from observations and all the products are also shown in each panel. The intraseasonal variability of $Q_{S}$ over the western Pacific is dominant due to the presence of high-level clouds (cloud amount over 40\%) and is concentrated over these moist convective regions [104]. TropFlux has the mean and SD close to TRITON observations, but CORE-II
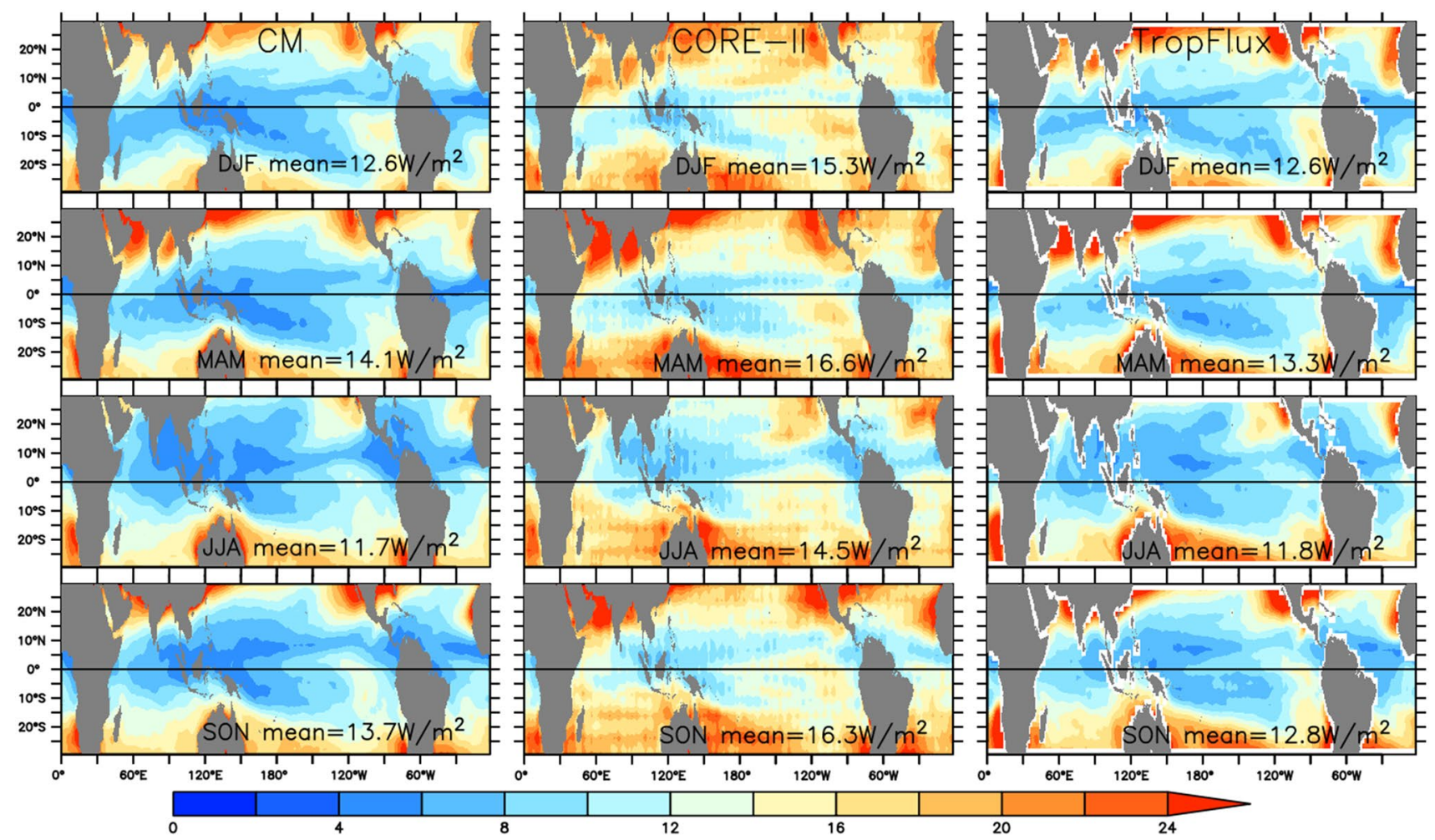

Fig. 5 Seasonal SD of downwelling longwave radiation $\left(\mathrm{Wm}^{-2}\right)$ from $\mathrm{CM}, \mathrm{CORE}-\mathrm{Il}$, and TropFlux in the global tropical oceans. Basin-averaged mean values are given in each sub panel

SN Applied Sciences 
Fig. 6 Frequency distribution of a downwelling shortwave $\left(\mathrm{Wm}^{-2}\right)$ and $\mathbf{b}$ downwelling longwave $\left(\mathrm{Wm}^{-2}\right)$ from TRITON and other reanalysis products
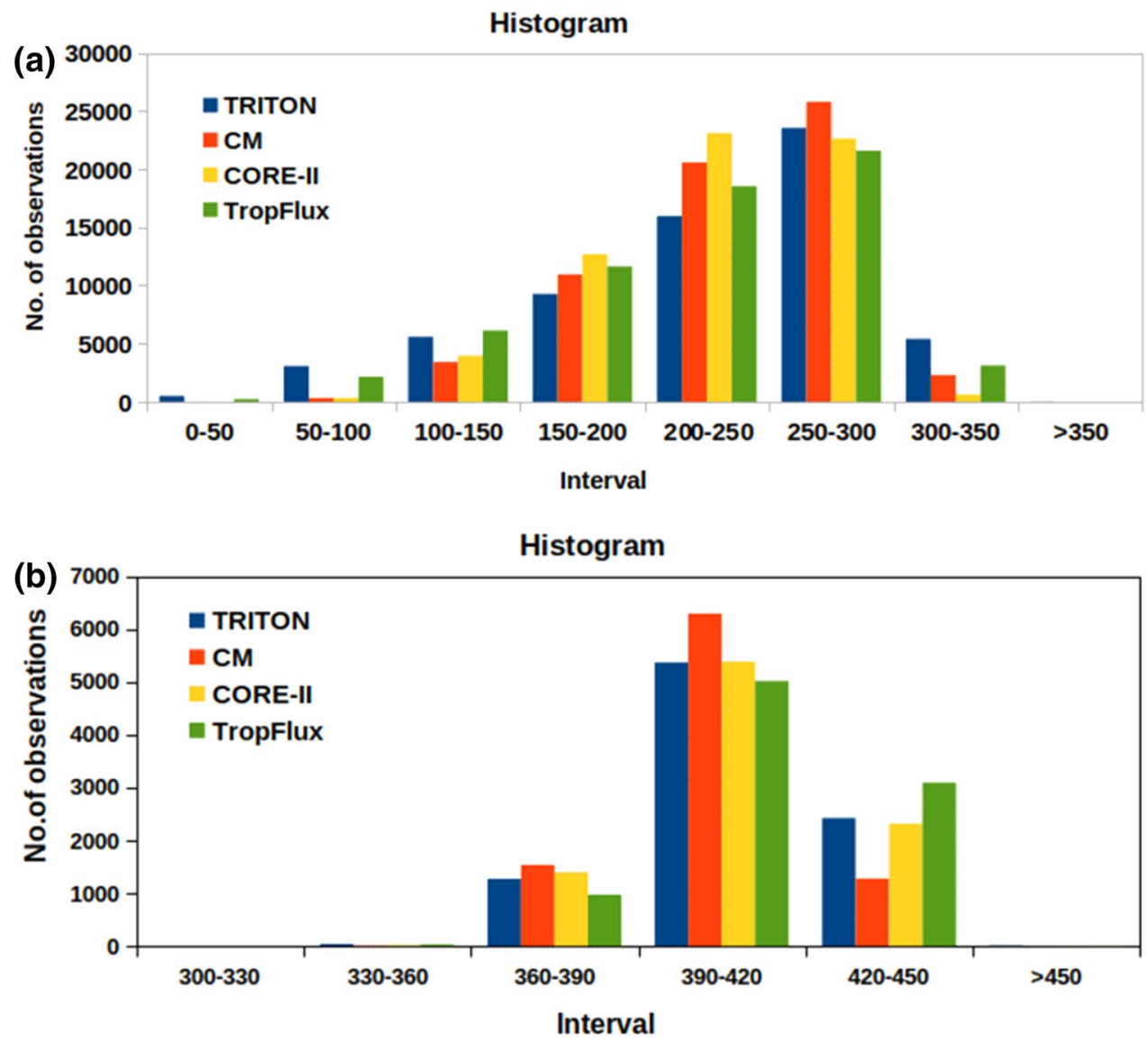

underestimated both the mean and SD. Although CM closely follows TRITON, it varies more with the observed SD (SD values are underestimated:Table 2). The seasonal cycle is prominent (Fig. 7c, d) in the central and eastern Pacific Oceans. This is due to the near absence of convective activity over the central and the eastern Pacific Oceans [25, $30,34,116]$. The observed mean $Q_{S}$ is the highest $(277.3$ $\mathrm{Wm}^{-2}$ ) at the central Pacific Ocean buoy location as compared to the eastern $\left(263 \mathrm{Wm}^{-2}\right)$ and the western Pacific Ocean buoy (243.7 $\left.\mathrm{Wm}^{-2}\right)$; and is due to the presence of subsidence regions with small total cloud amounts [104].

The time series comparison of $Q_{L}$ is shown in Fig. 8 for the same TRITON buoy locations as shown for $Q_{S}$. $Q_{L}$ in TRITON has large data gaps, and continuous data are available only from 2006. Some observations are available at $95^{\circ} \mathrm{W}$ during 2002-2003 (figure not shown). $Q_{L}$ shows constant variation throughout the year. Intraseasonal variability is noticed in all locations in all products. But, the seasonal cycles are not prominent in $Q_{L}$. TropFlux shows systematic positive bias over the western Pacific Ocean (Fig. 8a) with a mean bias of $\sim 10 \mathrm{Wm}^{-2}$. CM has better match with the observations over the western Pacific Ocean (Figs. 8a, b). But, CORE-II has systematic negative bias over the western Pacific Ocean and is overestimated in the eastern Pacific Ocean (Fig. 8d). This is followed by TropFlux. All products have underestimated the SD over the eastern Pacific Ocean.

Complete statistics of mean, bias, SD, and RMSE of $Q_{S}$ for all products compared with observations over the Pacific Ocean are shown in Table 2. CM overestimated the $Q_{S}$ with mean bias of $7.23 \mathrm{Wm}^{-2}$; TropFlux underestimated by $-4.62 \mathrm{Wm}^{-2}$. CORE-II has least mean bias of $-0.22 \mathrm{Wm}^{-2}$. Since the TropFlux using the GTMBA data in its bias corrections, $Q_{S}$ from TropFlux has the least daily RMSE of $36.58 \mathrm{Wm}^{-2}$, and it has the daily SD $\left(58 \mathrm{Wm}^{-2}\right.$ ) close to observation $\left(65 \mathrm{Wm}^{-2}\right)$. But, CORE-II has the least SD among all products. The satellite-derived product (CM) shows least RMSE of $40.41 \mathrm{Wm}^{-2}$ and is better than CORE-II (43.59 $\mathrm{Wm}^{-2}$ ). CM and CORE-II underrated the observed $Q_{L}$ with a bias of $-3.68 \mathrm{Wm}^{-2}$ and $-0.2 \mathrm{Wm}^{-2}$, respectively. $Q_{\mathrm{L}}$ from TropFlux has the positive bias of 3.35 $\mathrm{Wm}^{-2}$. SD of $Q_{\mathrm{L}}$ from both CORE-II and TropFlux (16.77 $\mathrm{Wm}^{-2}$ ) has better agreement with the observations (17.02 $\mathrm{Wm}^{-2}$ ). CM underestimated (SD $=13.92$ $\mathrm{Wm}^{-2}$ ) the observed SD values and has lower RMSE of 8.78 $\mathrm{Wm}^{-2}$ which is better than CORE-II $\left(11.94 \mathrm{Wm}^{-2}\right.$ ) and TropFlux $\left(10.56 \mathrm{Wm}^{-2}\right)$, respectively. CM has highest mean CC (average CC of both $Q_{S}$ and $Q_{L}$ ) (0.83) compared to CORE-II (0.82) and TropFlux (0.74). These values are consistent throughout the year since the values have 


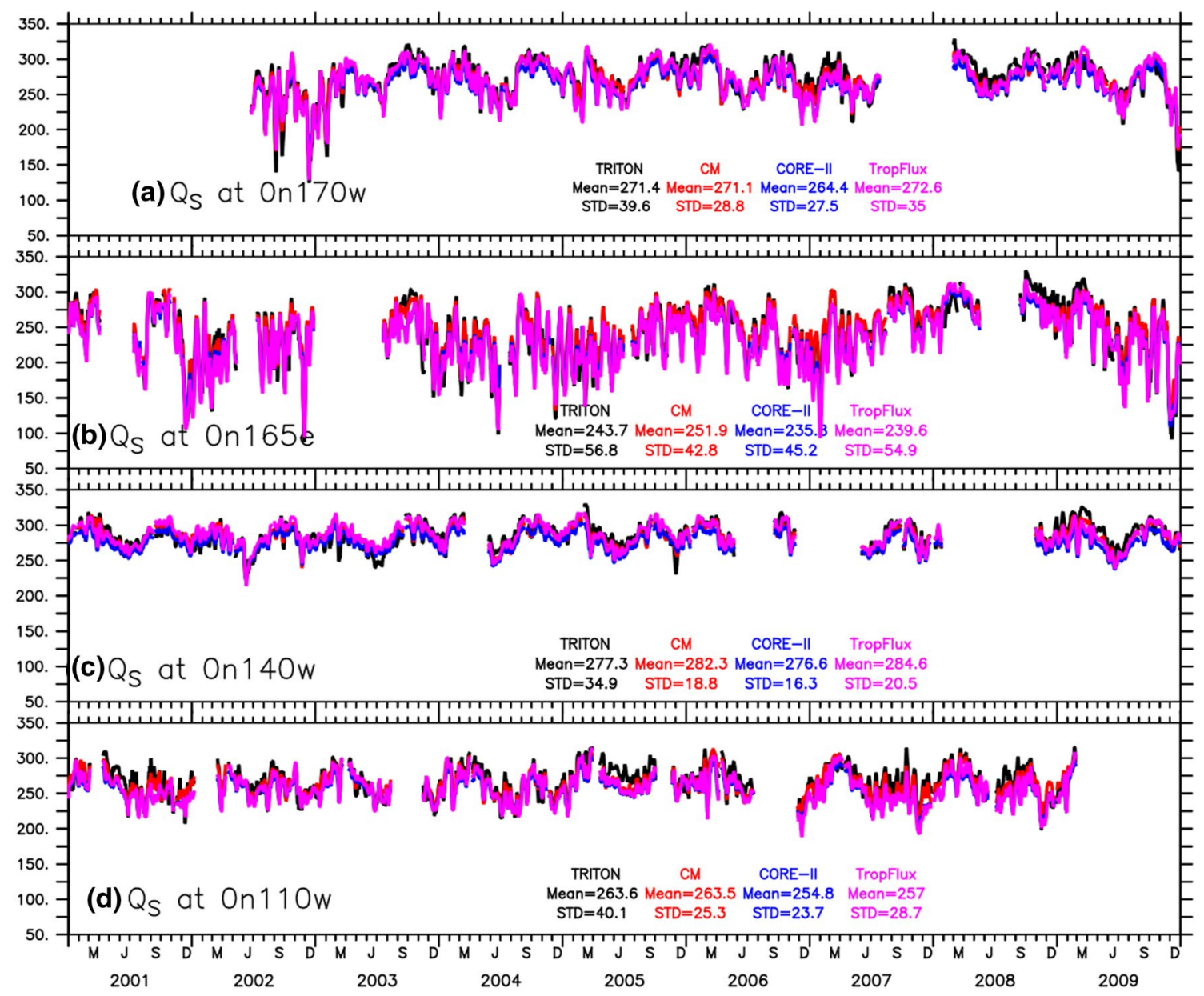

Fig. 7 Seven-day smoothed time series of downwelling shortwave $\left(\mathrm{Wm}^{-2}\right.$ ) from TRITON (black), CM (red), CORE-II (blue), and TropFlux (purple) from selected locations in the Pacific Ocean during 20012009. Mean and standard deviations (STD in the figure) $\left(\mathrm{Wm}^{-2}\right)$

similar magnitudes in different seasons (supplementary table S2).

\subsubsection{Atlantic Ocean}

Figure 9 shows the frequency distribution of $Q_{S}$ and $Q_{L}$ in the tropical Atlantic Ocean. Similar to Pacific Ocean, all the products overestimated the observed $Q_{S}$ in the 200-250 $\mathrm{Wm}^{-2}$ range of the frequency distribution in the Atlantic Ocean (Fig. 9a) and underestimated the lower $(<200$ $\mathrm{Wm}^{-2}$ ) and higher values $\left(>250 \mathrm{Wm}^{-2}\right)$. This result also corroborates the recent finding of Trolliet et al. [108] which shows the Meteosat satellite-based $Q_{S}$ overestimates the PIRATA observed values. Majority of $Q_{L}$ observations fall in $390-420 \mathrm{Wm}^{-2}$ range and CM is able to produce this trend better than other products. But, CM failed to match the observations in $420-450 \mathrm{Wm}^{-2}$ range (Fig. 9b). On the other hand, $Q_{L}$ variations significantly modify the net from TRITON observations and corresponding collocated and concurrent values from CM, CORE-II and TropFlux are also given in each panel

radiation at the sea surface; hence, the inability to capture the higher values will significantly affect estimating the energy transfer at the sea surface and hence the SST variations.

The time series comparison of $Q_{S}$ from all products with observations (PIRATA buoy locations) is shown in Fig. 10. All products are able to reproduce buoy observed daily variations. Daily $Q_{S}$ variations over the western Atlantic Ocean are shown in Fig. 10a. The prominent annual cycle embedded with ISOs is seen during the evaluation period (2001-2009). Observed lower values in 2003 could be erroneous which was also pointed out by Trolliet et al. [108] and also by our own assessment by checking the consistency with the other year's variations. The similar errors were observed both in $Q_{S}$ and $Q_{L}$ at several locations in all three tropical oceans during different years (figures not shown). Most of these errors are corrected by the quality control and data distribution team of GTMBA 


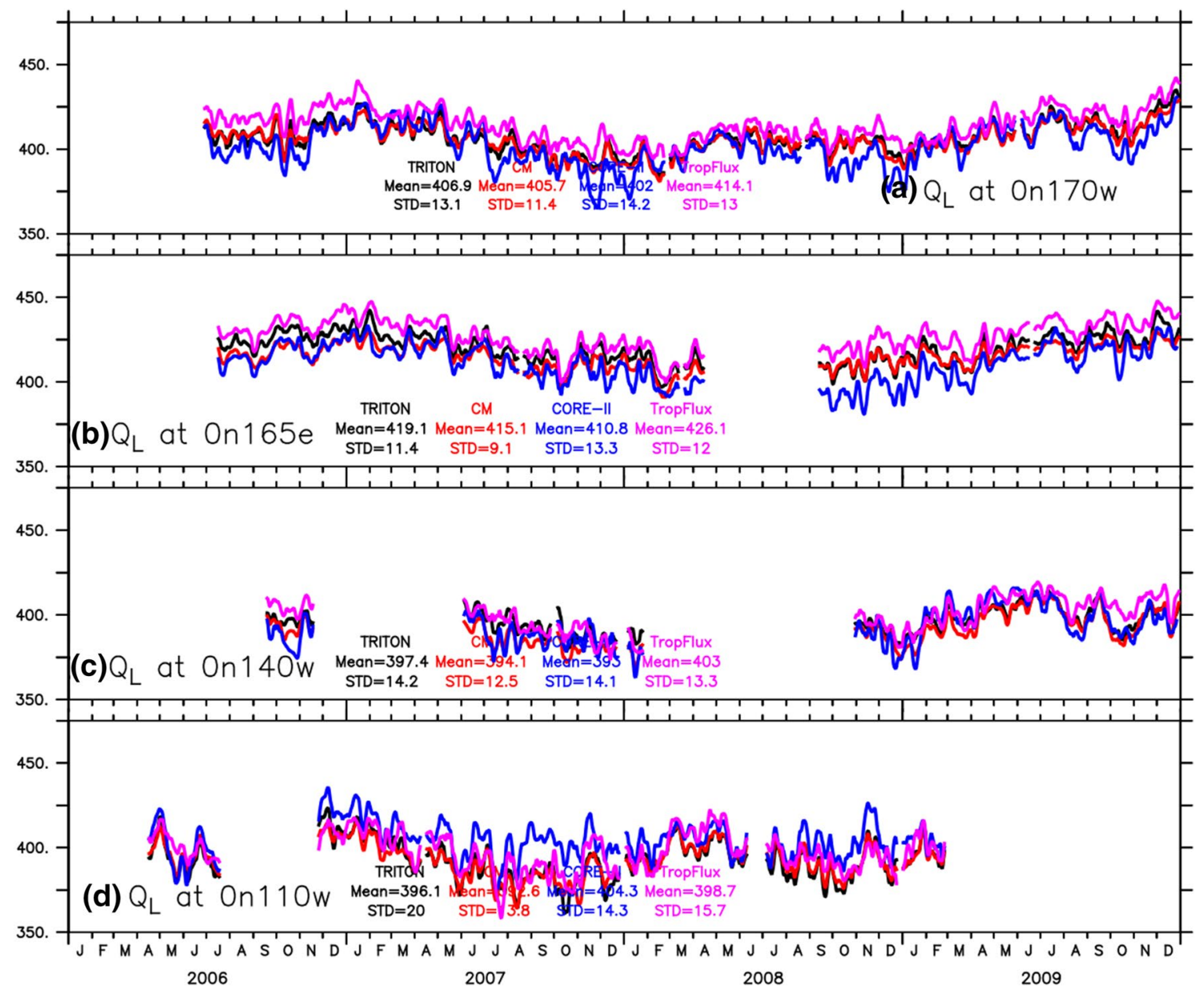

Fig. 8 Seven-day smoothed time series of downwelling longwave $\left(\mathrm{Wm}^{-2}\right.$ ) from TRITON (black), CM (red), CORE-II (blue), and TropFlux (purple) from selected locations in the Pacific Ocean during 20062009. Mean and standard deviations (STD in the figure) $\left(\mathrm{Wm}^{-2}\right)$

through the feedback during our study. The buoy location at $15^{\circ} \mathrm{N}$ and $38^{\circ} \mathrm{W}$ is almost in the fringe location of summer ITCZ (Maloney and Shaman 2008). Seasonal cycle with embedded ISO variations is very prominent at the central Atlantic Ocean buoy location (Fig. 10b). Also, all products could able to capture the daily buoy observed $Q_{S}$ at this location. This buoy location at the equatorial Atlantic Ocean experiences the presence of both summer and winter ITCZ in the Atlantic Ocean. Hence, the intraseasonal activity is significant in this location among all other locations shown in Fig. 10 [105]. The seasonal cycle is dominant in the off-equatorial eastern Atlantic Ocean buoy location with near absence of any ISO activity (Fig. 10c). This buoy is located off ITCZ locations both in summer and winter, and hence the $Q_{S}$ variation follows the seasonal migration of Sun [105]. The daily variation of $Q_{S}$ at the near-equatorial Atlantic Ocean from buoy observations and all the products are shown in Fig. 10d. All the products are able to from TRITON observations and corresponding collocated and concurrent values from CM, CORE-II and TropFlux are also given in each panel

capture the daily variations, yet fail to capture the lower observed values of $Q_{S}$ which can also be seen in Fig. 9a.

Figure 11 shows the time series comparison for $Q_{L}$ over the western $\left(38^{\circ} \mathrm{W}\right)$, the central $\left(23^{\circ} \mathrm{W}\right)$ and the eastern $\left(10^{\circ} \mathrm{W}\right)$ Atlantic Ocean. $Q_{\mathrm{L}}$ also has the prominent annual cycle over the western and the central Atlantic Oceans. The presence of ISOs is also observed over the eastern Atlantic Ocean in the observations which are well captured by all the products.

Statistical analysis performed with the collocated data from all buoys is given in Table 3. $Q_{S}$ in TropFlux shows better agreement with observations among all the datasets evaluated. CM has the highest positive bias $\left(5 \mathrm{Wm}^{-2}\right)$ in $Q_{\mathrm{S}}$ and negative bias in $Q_{\mathrm{L}}\left(-3.76 \mathrm{Wm}^{-2}\right)$, followed by CORE-II $\left(Q_{S}=2.22 \mathrm{Wm}^{-2}, Q_{\mathrm{L}}=-1.12 \mathrm{Wm}^{-2}\right) . Q_{\mathrm{S}}$ in TropFlux has least negative bias of $-0.45 \mathrm{Wm}^{-2}\left(Q_{\mathrm{L}}=0.89 \mathrm{Wm}^{-2}\right)$, and CORE-II has large RMSE $\left(39.6 \mathrm{Wm}^{-2}\right)$ values compared to other products (CM: $34.8 \mathrm{Wm}^{-2}$; TropFlux: $32.2 \mathrm{Wm}^{-2}$ ). 
Fig. 9 Distribution of a downwelling shortwave radiation $\left(\mathrm{Wm}^{-2}\right)$ and $\mathbf{b}$ downwelling longwave radiation $\left(\mathrm{Wm}^{-2}\right)$ from PIRATA and other reanalysis products available during 2001-2009
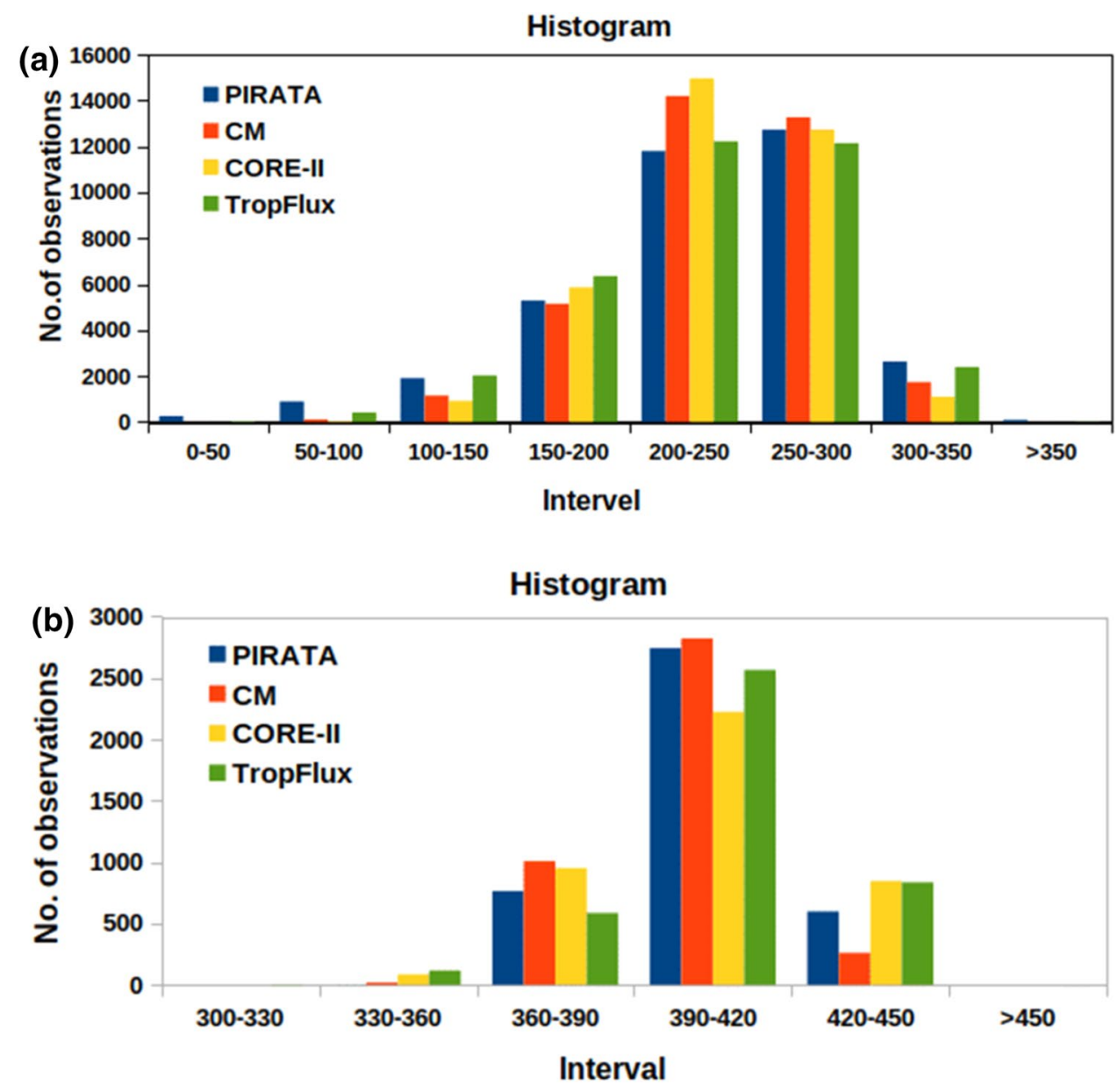

$\mathrm{SD}$ of $Q_{S}$ is low $\left(39.9 \mathrm{Wm}^{-2}\right)$ in CORE-Il compared to other products and observations $\left(56.7 \mathrm{Wm}^{-2}\right)$. Analogous to the Pacific Ocean, CM outplayed other reanalysis/hybrid $Q_{L}$ datasets in the Atlantic with highest CC value of 0.83 , followed by CORE-II and TropFlux with 0.71 and 0.64 , respectively (Table 3). Similar to the Pacific Ocean, TropFlux shows highest CC of 0.83 in $Q_{S}$, followed by CM (0.79) and CORE-II (0.72). Despite the changes in different statistical parameter values in seasons (supplementary table S3), all the parameters closely follow the annual values (Table 3 ).

\subsubsection{Indian Ocean}

The Indian Ocean differs from the Pacific and the Atlantic Oceans in numerous ways. Indian Ocean is landlocked in the north by the Asian continent, thus driving the strongest monsoon on the Earth. In recent years, there are several studies focusing on understanding the role of the Indian Ocean in the climate change $[92,94,95])$. The GTMBA program in the Indian Ocean (RAMA) was initiated much later than that of in the Atlantic and Pacific Oceans. This program aims to study the role of the Indian Ocean on the Asian monsoon and on the global climate [63]. The
SST variability in the north Indian Ocean is mainly determined by the net heat flux on seasonal and ISO time scale $[47,98]$. Errors associated with the $Q_{S}$ and $Q_{L}$ would affect the net heat flux computation and hence the SST. We also compared the $Q_{S}$ and $Q_{L}$ from CM, CORE-II and TropFlux over the north Indian Ocean. Shahi et al. [99] showed the evaluation of net shortwave radiation over the north Indian Ocean. This product was generated using buoy and satellite-derived outgoing longwave radiation data with an empirical relationship. As per best of our knowledge, no studies are available over the Indian Ocean documenting the errors in $Q_{S}$ and $Q_{L}$ from existing satellite, reanalysis or hybrid products on daily time scale.

$Q_{S}$ observations are available over 18 locations, and only 3 locations contain $Q_{L}$ during 2001-2009 in the Indian Ocean. Hence, the availability of $Q_{L}$ is low in the Indian Ocean. Frequency distribution of downwelling radiation data in the Indian Ocean is similar to TRITON and PIRATA (Fig. 12). $Q_{S}$ in $C M$ is close to observed distribution from RAMA (Fig. 12a) and is near Gaussian and is unlike its skewed nature in TRITON (Pacific Ocean) and PIRATA (Atlantic Ocean). $Q_{S}$ in both CORE-II and TropFlux has overestimated the observations in $150-250 \mathrm{Wm}^{-2}$ range, 


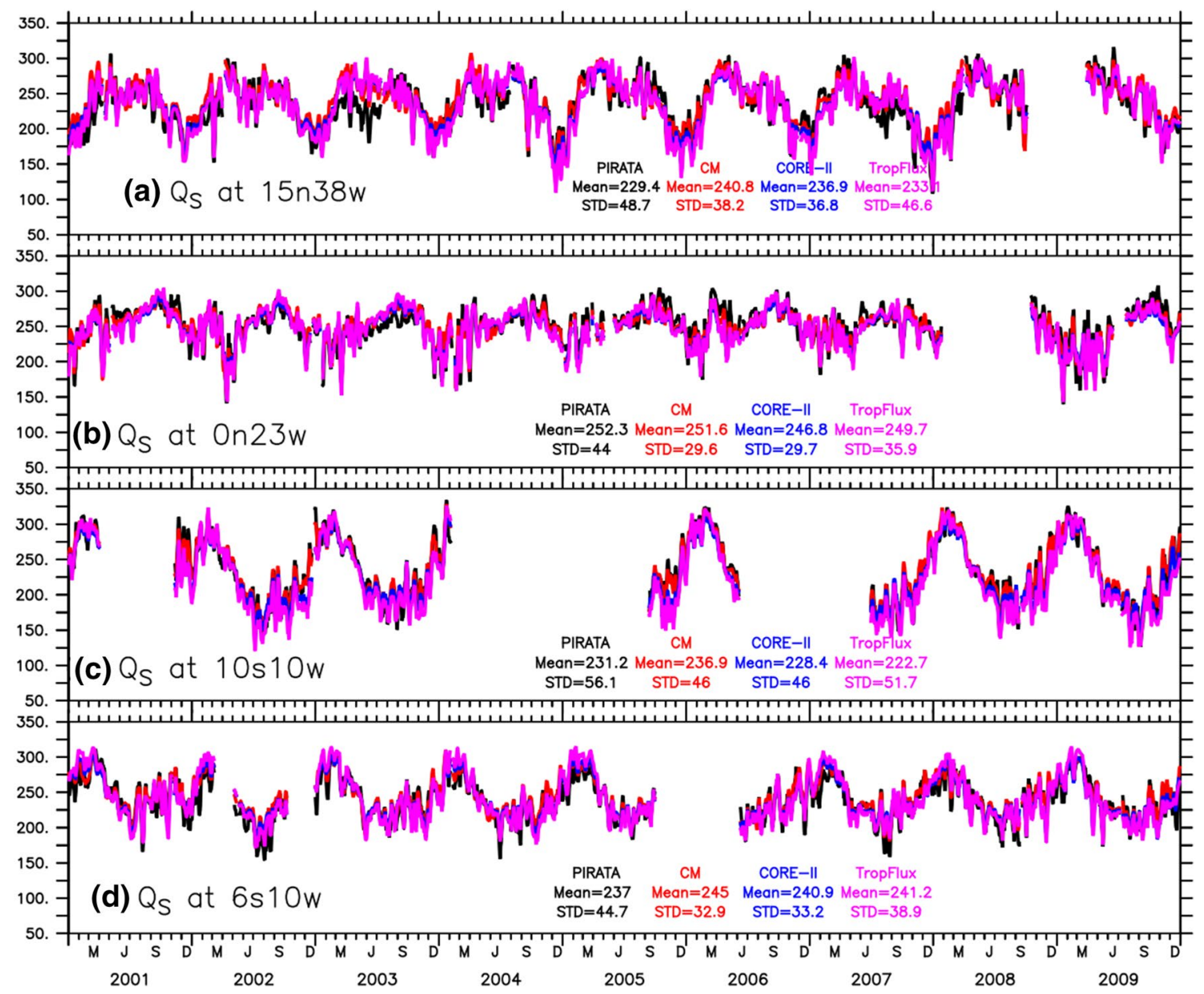

Fig. 10 Seven-day smoothed time series of downwelling shortwave radiation $\left(\mathrm{Wm}^{-2}\right.$ ) from PIRATA (black), CM (red), CORE-II (blue), and TropFlux (purple) from OLR (green) from selected locations in the Atlantic Ocean during 2001-2009. Mean and standard devia- tions (STD in the figure) $\left(\mathrm{Wm}^{-2}\right)$ from PIRATA observations and corresponding collocated and concurrent values from CM, CORE-II and TropFlux are also given in each panel

of $Q_{S}$ particularly over the central Bay of Bengal and the eastern equatorial Indian Ocean. Figure 14 shows the daily variation of $Q_{L}$ during 2008 and 2009. Peak values reached to $450 \mathrm{Wm}^{-2}$ in the central Bay of Bengal during summer monsoon season. This is mainly due to the presence of deep convective clouds over this region $[76,89,133]$. None of the buoys in the Atlantic or the Pacific Oceans shows this high $Q_{L}$ values. The presence of the strong convective activity over the western Pacific Ocean warm pool region $[115,130,131]$ also contributes to high $Q_{L}$ values (Fig. 8b). Dips in $Q_{S}$ and $Q_{L}$ in Fig. 14 correspond to the intense precipitation events and deep cloud cover [81]. Rahaman and Ravichandran [81] showed a linear relationship between drop in air temperature and the rainfall events. The direct and indirect effects of anthropogenic aerosols and cloudiness also contribute to these changes [132]. Wang [119] highlighted the dusty air conditions and the rainy weather characteristics for the larger model errors in predicting the 


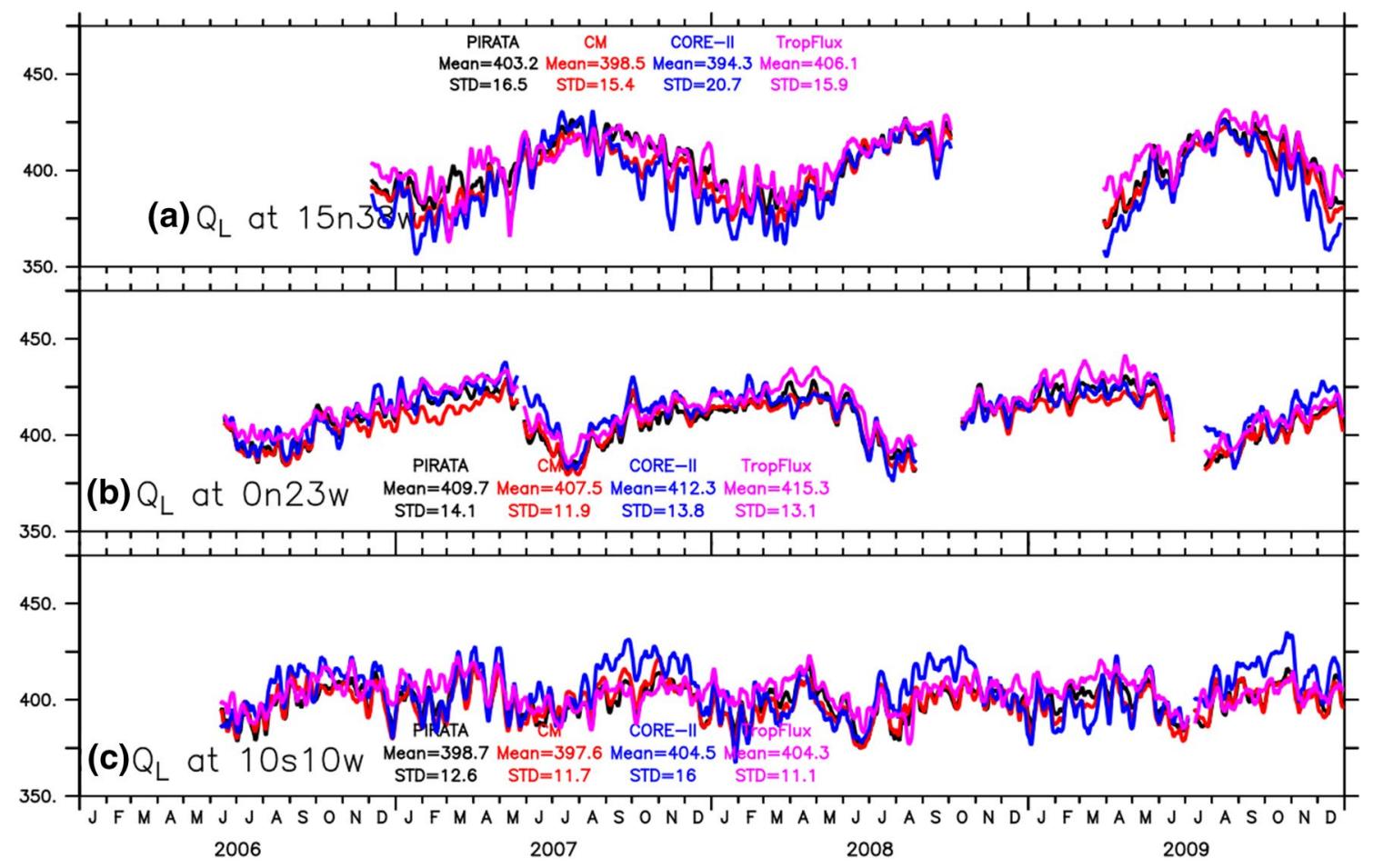

Fig. 11 Seven-day smoothed time series of downwelling longwave radiation $\left(\mathrm{Wm}^{-2}\right)$ from PIRATA (black), CM (red), CORE-II (blue), and TropFlux (purple) from the selected locations in the Atlantic Ocean during 2006-2009. Mean and standard deviations (STD in the fig- ure) $\left(\mathrm{Wm}^{-2}\right)$ from PIRATA observations and corresponding collocated and concurrent values from CM, CORE-II and TropFlux are also given in each panel

shows better aggregate $\mathrm{CC}(0.83)$ than any other product in the Indian Ocean, followed by CM with CC of 0.78 . Highest $C C$ value $(0.94)$ in $C M$ for $Q_{L}$ in the Indian Ocean also highlights its accuracy in estimating the $Q_{L}$ in the global tropical oceans. Like in other oceans, these values are consistent over the Indian Ocean throughout the year. Summary of seasonal statistics for all the products are given in supplementary material (S4). Unlike the Pacific and the Atlantic Oceans, the Indian Ocean shows the highest and lowest CC values in different seasons for different products (refer S4 in supplementary material). CORE-II shows the highest CC in DJF, CM in SON (0.79), and TropFlux in JJA (0.85). $Q_{S}$ from TropFlux shows strong daily variability with observations in this region. Similar to the Atlantic and the Pacific Oceans, $C M$ in the Indian Ocean shows highest aggregate CC for $Q_{L}$ (0.91), followed by TropFlux, and CORE-II. Seasonal CC values of $Q_{L}$ in CM are also greater than 0.9 in DJF, MAM, and JJA seasons. Both CORE-II and TropFlux show the highest CC for $Q_{L}$ in DJF, and lowest in JJA.

\subsection{Probable SST error associated with the $Q_{S}$ and $Q_{L}$ error}

Tropical oceans show a number of modes of climate variability, ranging from intraseasonal-to-interannual and 
Fig. 12 Frequency distribution of a downwelling shortwave radiation $\left(\mathrm{Wm}^{-2}\right)$ and $\mathbf{b}$ downwelling longwave radiation $\left(\mathrm{Wm}^{-2}\right)$ from RAMA and other reanalysis products during 2001-2009

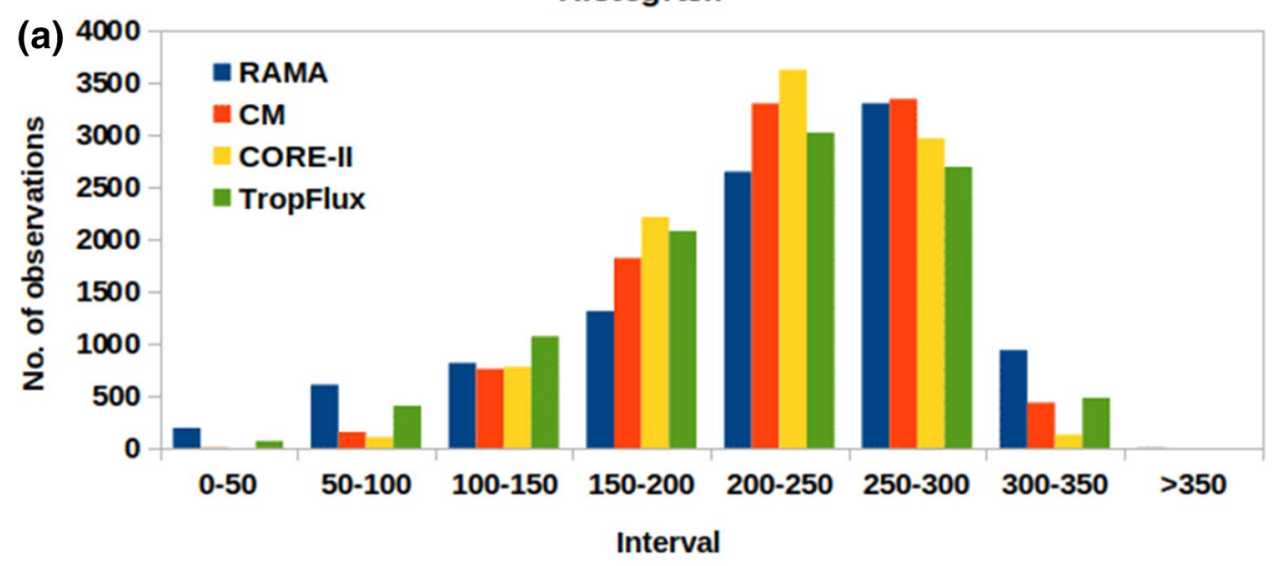

Histogram

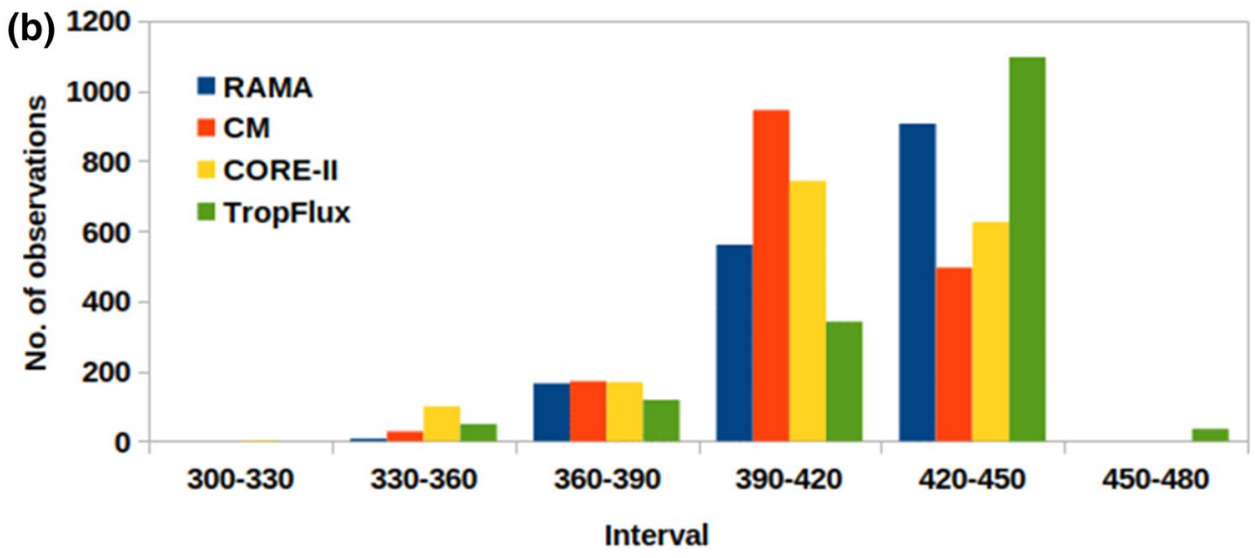

decadal time scales $[10,46,84]$. SST anomalies play an important role in upper ocean, lower atmospheric variability and predictability [11, 39, 100, 106, 114]. Factors causing the SST anomalies could also cause temporal and spatial discrepancies in several atmosphere-ocean parameters due to lack of air-sea coupling. These SST anomalies can also induce anomalous convection through surface evaporation and low-level moisture convergence [45]. A large positive simultaneous correlation between rainfall and SST indicate that the SST is forcing the atmosphere, and the atmosphere response to SST forcing is relatively fast [125]. The anomalous atmospheric convection through cloud radiation, wind-evaporation, wind-induced oceanic mixing and upwelling causes the SST to change. These atmospheric feedbacks can be detected in the SST tendency. In the central and the eastern tropical Pacific Oceans, the observed SST anomalies are mainly due to oceanic processes $[36,38]$. Atmospheric forcing plays an important role in modulating SST anomalies in the extratropics and in the tropical Indo-Western Pacific Ocean regions $[3,49,54,56,57,118]$. SST in the north Indian Ocean is also mainly modulated by net heat flux $[47,98]$. Therefore, detailed representation of SST requires a better quantification of upper ocean processes and atmospheric forcing. Furthermore, the discrepancy in reproducing the evolution of seasonal SST in coupled models leads to bias in the spatial and temporal distribution of precipitation [14]. Chowdhury et al. [14] showed that the processes responsible for SST tendency differ from region to region over the tropical Indian Ocean. Yet, errors involved in advection and heat flux over the tropical Indian Ocean is mainly responsible for the distortion of seasonal SST change in the coupled models. Thus, it is essential to evaluate the role of different fluxes on SST and mixed layer. In this study, we estimated the error in mixed layer temperature due to error in $Q_{S}$ and $Q_{L}$. The mixed layer temperature or SST tendency equation is given as

$\frac{\partial T_{\mathrm{m}}}{\partial t}=\frac{Q_{0}-Q_{\mathrm{p}}}{\rho C_{\mathrm{p}} H_{\mathrm{m}}}+\frac{W_{\mathrm{e}}\left(T_{\mathrm{m}}-T_{\mathrm{b}}\right)}{H_{\mathrm{m}}}-U \cdot \nabla T_{\mathrm{m}}-K_{\mathrm{z}}+\frac{\partial^{2} T_{\mathrm{m}}}{\partial z^{2}}+$ Res

where $T_{\mathrm{m}}$ denotes mixed layer temperature. $K_{\mathrm{z}}$ is the coefficient of vertical diffusion of heat $\left(0.1 \times 10^{-4} \mathrm{~m}^{2} \mathrm{~s}^{-1}\right)$. Res is residual term. $W_{e}$ is the entrainment rate $(\mathrm{m} / \mathrm{s})$, and $T_{\mathrm{b}}$ is the temperature at the bottom of mixed layer [17, $79,80] . \partial T_{m} / \partial t$ is the rate of change of $T_{m}, \rho$ is seawater 


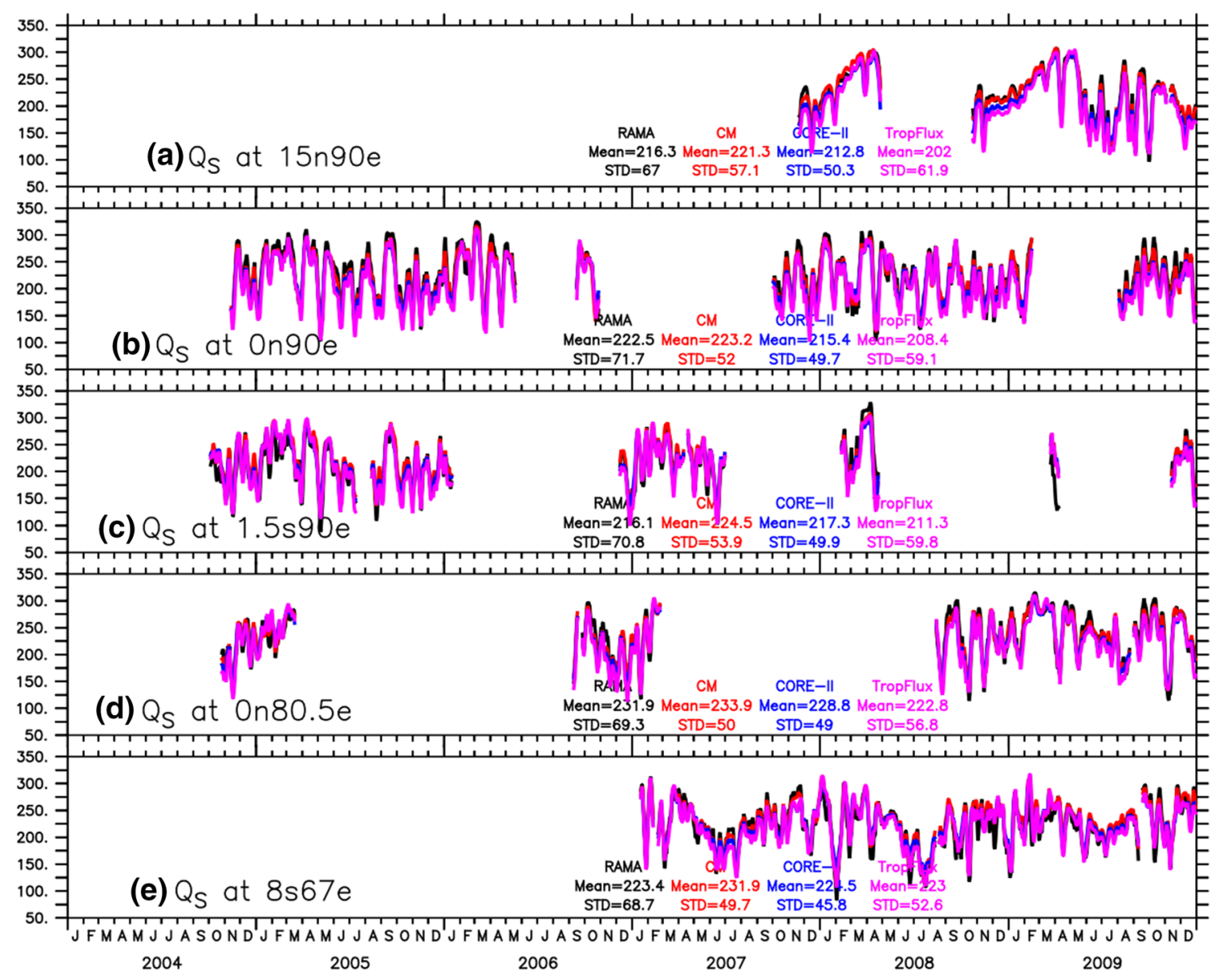

Fig. 13 Seven-day smoothed time series of downwelling shortwave radiation $\left(\mathrm{Wm}^{-2}\right.$ ) from RAMA (black), CM (red), CORE-II (blue), and TropFlux (purple) from the selected locations in the Indian Ocean during 2004-2009. Mean and standard deviations (STD in

density $\left(1024 \mathrm{kgm}^{-3}\right), C_{\mathrm{p}}$ is heat capacity of seawater (3993 $\mathrm{J} \mathrm{kg}^{-1}{ }^{\circ} \mathrm{C}^{-1}$ ), and $H_{\mathrm{m}}$ is mixed layer depth. $Q_{0}$ is the net surface heat flux $\left(\mathrm{Wm}^{-2}\right)$, and $Q_{\mathrm{p}}$ is the shortwave radiation $\left(\mathrm{Wm}^{-2}\right)$ penetrating below the mixed layer [14].

If heat fluxes are solely responsible for the SST change, then only the first term in the above equation is dominant and all other term can be discarded. We assume this approximation to show the maximum possible errors involved in SST tendency due to $Q_{S}$ and $Q_{L}$ RMSE. We assume the errors associated with corresponding $Q_{S}$ and $Q_{\mathrm{L}}$ as net radiative heat flux, i.e. $\left(Q_{0}-Q_{\mathrm{p}}\right)$ in the above equation. The maximum monthly errors caused by the $Q_{S}$ and $Q_{L}$ in the global oceans are given in Table 5.

We have selected a few representative stations, i.e., $0^{\circ} \mathrm{N}, 80.5^{\circ} \mathrm{E}$ in the Indian Ocean, $0^{\circ} \mathrm{N}, 23^{\circ} \mathrm{W}$ in the Atlantic Ocean and $0^{\circ} \mathrm{N}, 110^{\circ} \mathrm{W}$ (east) and $0^{\circ} \mathrm{N}, 165^{\circ} \mathrm{E}$ (west) in the Pacific Ocean. The monthly mixed layer depths (MLD) are the figure) $\left(\mathrm{Wm}^{-2}\right)$ from RAMA observations and corresponding collocated and concurrent values from CM, CORE-II and TropFlux are also given in each panel

computed using the monthly vertical temperature profiles [41]. A reference depth of $10 \mathrm{~m}$, including temperature gradient criteria $\Delta T=0.8^{\circ} \mathrm{C}$, is used to compute the MLD from monthly temperature profiles available from TRITON, PIRATA and RAMA buoy locations. In the western Pacific Ocean, the annual average of MLD is $97 \mathrm{~m}$ and shows the highest MLD of $122 \mathrm{~m}$ in December and lowest of $87 \mathrm{~m}$ in September. In the eastern Pacific Ocean $\left(0^{\circ} \mathrm{N}\right.$, $\left.110^{\circ} \mathrm{W}\right)$, the MLD is shallower than the western Pacific Ocean with annual average being $30 \mathrm{~m}$ and has the highest MLD of $35 \mathrm{~m}$ in November and lowest of $25 \mathrm{~m}$ in March. In the Atlantic Ocean, at $0 \mathrm{~N}, 23 \mathrm{~W}$; the annual average of MLD is $47 \mathrm{~m}$ with highest and lowest of $77 \mathrm{~m}$ and $35 \mathrm{~m}$, in October and March, respectively. In the Indian Ocean, MLD has annual average value of $80 \mathrm{~m}$ at $0^{\circ} \mathrm{N}, 80.5^{\circ} \mathrm{E}$ with highest of $100 \mathrm{~m}$ in November and lowest of $60 \mathrm{~m}$ in March. Corresponding RMSE of $Q_{S}$ and $Q_{L}$ at each location is used 


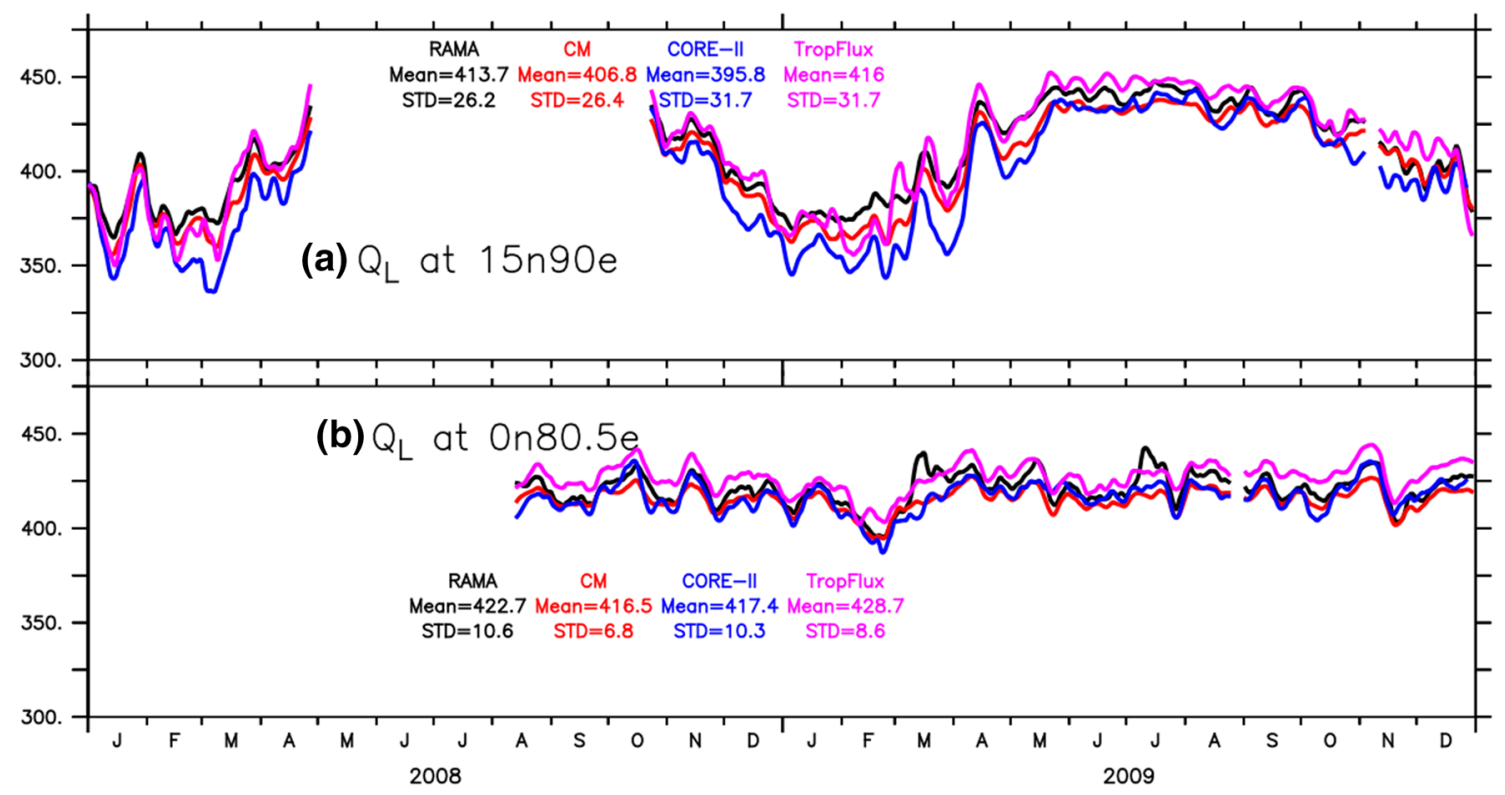

Fig. 14 Seven-day smoothed time series of downwelling longwave radiation $\left(\mathrm{Wm}^{-2}\right)$ from RAMA (black), CM (red), CORE-II (blue), and TropFlux (purple) from the selected locations of $Q_{L}$ in the during 2008-2009. Mean and standard deviations (STD in the figure) $\left(\mathrm{Wm}^{-2}\right)$ from RAMA observations and corresponding collocated and concurrent values from CM, CORE-II and TropFlux are also given in each panel

Table 5 SST error per month (in ${ }^{\circ} \mathrm{C}$ ) associating with errors in downwelling shortwave radiation $\left(Q_{S}\right.$ ) and downwelling longwave radiation $\left(Q_{L}\right)$

\begin{tabular}{|c|c|c|c|c|c|c|c|c|c|c|c|c|}
\hline \multirow[t]{3}{*}{ Product/location } & \multicolumn{6}{|l|}{$Q_{S}$} & \multicolumn{6}{|l|}{$Q_{\mathrm{L}}$} \\
\hline & \multicolumn{2}{|l|}{$\mathrm{CM}$} & \multicolumn{2}{|c|}{ CORE-II } & \multicolumn{2}{|c|}{ TropFlux } & \multicolumn{2}{|l|}{$\mathrm{CM}$} & \multicolumn{2}{|c|}{ CORE-II } & \multicolumn{2}{|c|}{ TropFlux } \\
\hline & RMSE & SST error & RMSE & SST error & RMSE & SST error & RMSE & sst error & RMSE & SST error & RMSE & SST error \\
\hline $0 \mathrm{~N}, 110 \mathrm{~W}$ & 14.35 & 0.30 & 14.11 & 0.30 & 16.88 & 0.36 & 8.06 & 0.17 & 7.68 & 0.16 & 8.84 & 0.19 \\
\hline $0 \mathrm{~N}, 165 \mathrm{E}$ & 26.54 & 0.17 & 25.98 & 0.17 & 31.48 & 0.21 & 6.33 & 0.04 & 9.74 & 0.06 & 8.55 & 0.06 \\
\hline $0 \mathrm{~N}, 23 \mathrm{~W}$ & 18.53 & 0.25 & 18.65 & 0.25 & 22.19 & 0.30 & 10.45 & 0.14 & 10.65 & 0.14 & 11.44 & 0.15 \\
\hline $0 \mathrm{~N}, 80.5 \mathrm{E}$ & 24.51 & 0.18 & 24.54 & 0.18 & 28.73 & 0.21 & 3.7 & 0.03 & 5.96 & 0.03 & 5.05 & 0.04 \\
\hline
\end{tabular}

to estimate the error in SST along with the annual averaged MLD values (Table 5 ).

The maximum monthly error in SST due to error in $Q_{S}$ and $Q_{L}$ is shown in Table 5. RMSE in $Q_{S}$ in all products is large over the western Pacific Ocean $\left(27 \mathrm{Wm}^{-2}\right)$ followed by the Indian Ocean and the Atlantic Ocean (Table 5). Highest SST error $\left(0.36^{\circ} \mathrm{C}\right.$ per month) arises due to error in $Q_{5}$, and is over the eastern Pacific Ocean in TropFlux products followed by low SST error of $0.30^{\circ} \mathrm{C}$ in CM and CORE-II products, respectively. Same is the case in other regions with difference in magnitudes. Monthly error in SST due to error in $Q_{L}$ from TropFlux is also high over the eastern Pacific Ocean with $0.19{ }^{\circ} \mathrm{C}$ and is followed by $\mathrm{CM}$ and CORE-II. The Indian Ocean shows least monthly SST errors due to errors in $Q_{L}$ in all the products. On average, $Q_{L}$ from $\mathrm{CM}$ shows the least error in all three global tropical oceans.

\section{Summary and conclusions}

The weather and climate over the global tropical ocean are mainly modulated by the net heat flux variation at the sea surface. The turbulent and the radiative heat fluxes at the sea surface determine the net heat flux variability. Different observations and reanalysis-based radiative heat flux products are available to study the net heat flux variability and to force the OGCMs as a surface boundary condition. Considerable progress has been made to improve the accuracy and reliability of these products $[9,12,52$, 109]. However, many of these gridded products have not been quantitatively evaluated with the independent reliable data sources. Particularly, this exercise is essential over the tropical oceans to understand the weather and climate variability in a better way by using these gridded 
products. Thus, it is important to fill this gap by evaluating the most commonly used radiative forcing datasets with the independent in situ observations. Hence, in this study we evaluated the daily downwelling shortwave $\left(Q_{S}\right)$ and longwave $\left(Q_{\mathrm{L}}\right)$ radiation at the sea surface from satellitederived and corrected reanalysis products with GTMBA in situ observations in the tropical oceans.

Daily data from MODIS/CERES (CM) satellite estimations, CORE-II, and TropFlux products during 2001-2009 are used in this study. To the best of our knowledge, there are only a few studies available over the tropical oceans documenting the errors in $Q_{S}$ and $Q_{L}$ from existing satellite, reanalysis, hybrid or blended products with limitations in parameters used, spatial extent and period of evaluation [108]. This study is also first of its kind to evaluate $Q_{S}$ and $Q_{L}$ from ISCCP data (TropFlux) and recent satellite-based product from CERES/MODIS (CM) in all three tropical oceans using in situ measurements. Furthermore, as per our knowledge there is no study exists on long-term evaluation (for a decade) of radiative fluxes from these three products with in situ data in all three tropical oceans.

The frequency distribution of $Q_{S}$ shows that the majority of $Q_{S}$ observations as well as derived products lie in 200-300 $\mathrm{Wm}^{-2}$ range in all the three tropical oceans. All products overestimated majority of the observations both in $Q_{S}$ and $Q_{L}$. However, they underestimated the lower range $\left(0-100 \mathrm{Wm}^{-2}\right)$ values in $Q_{S}$ and higher range (300-440 $\mathrm{Wm}^{-2}$ ) values in $Q_{\mathrm{L}}$. This suggest that the existing biases in $Q_{S}$ and $Q_{L}$ in estimating lower and upper range values in all three products used in this study may have significant effect on the SST simulation. Majority of the $Q_{L}$ observations lie within $390-450 \mathrm{Wm}^{-2}$ range and $\mathrm{CM}$ slightly overestimated the observed distribution in the Pacific and the Atlantic Oceans. But, the observations lie within $420-450 \mathrm{Wm}^{-2}$ range in the Indian Ocean. This implies that the tropical Indian Ocean receives $30 \mathrm{Wm}^{-2}$ more energy as compared to the tropical Pacific and the Atlantic Oceans in the form of downwelling longwave radiation. Although TropFlux is able to capture this distribution, CM and CORE-II have more biases as compared to observation. The daily $Q_{S}$ variation shows dominant seasonal cycle over the off-equatorial eastern Pacific Ocean, however intraseasonal variation is more prominent throughout the year in the western Pacific Ocean, and is embedded within the seasonal variations. The presence of intraseasonal oscillations (ISO) activity throughout the year at this location is mainly due to the presence of summer and winter intertropical convergence zone (ITCZ). The observed variability is more accurately reproduced by TropFlux and is less in CORE-II in the Pacific Ocean (Fig. 7, Table 2). The mean bias is least in CORE-II products, with highest RMSE value and least CC values. At the same time, TropFlux has least RMSE. This lower RMSE value in TropFlux product may be due to the use of GTMBA data in TropFlux corrections. CM performance lie in between CORE-II and TropFlux (Fig. 7, Table 2). No clear seasonality is observed in $Q_{L}$ either in observations or in any other hybrid products. Intraseasonal variations are dominant in the Pacific Ocean and prominent in all seasons. TropFlux systematically overestimated the $Q_{L}$ over the Pacific Ocean but accurately captured the variability (Fig. 8, Table 2). CM shows the observed daily variation with least RMSE and highest CC values (Fig. 8, Table 2).

Daily $Q_{S}$ over the western Atlantic Ocean shows clear annual cycle embedded with ISOs. All the products captured this variation (Fig. 10a). Similar variation is seen in the central Atlantic Ocean (Fig. 10b) with the presence of more prominent ISO activity. This buoy location at the equatorial Atlantic Ocean exposed to both summer and winter ITCZ, and hence the intraseasonal activity is most prominent in this location in the Atlantic Ocean. Seasonal cycle is dominant with near absence of any ISO activity in the off-equatorial eastern Atlantic Ocean (Fig. 10c, d) since it is located in the shadow region of ITCZ. All products show this observed variation. However, all products underestimated the variability and have lower SD values compared to observations. TropFlux closely follows the observations compared to CORE-II and CM (Fig. 10, Table 3) and has least RMSE, mean bias and highest CC values. Similar to the Pacific Ocean, CM in the Atlantic Ocean also has moderate SD, CC and RMSE which lie between COREII and TropFlux (Table 3). These results are not seasonally dependent, since the statistical values are consistent in all seasons with no major changes ( $S 2$ and $S 3$ ). $Q_{L}$ has the dominant seasonal cycle over the western Atlantic Ocean and prominent ISO over the eastern Atlantic Ocean. All products are able to capture the observed daily variation for $Q_{L}$ in the Atlantic Ocean. CORE-II overestimated the variability with larger SD compared to observations (Fig. 11, Table 4). Like in the Pacific Ocean, $Q_{L}$ from CM in the Atlantic Ocean also has least RMSE and highest CC compared to CORE-II and TropFlux and also shows the observed variability (Table 3).

The Indian Ocean is dominated by the presence of prominent ISO in contrast to the Pacific and the Atlantic Oceans where the seasonal cycle is dominant. All the products captured this ISO. CM shows observed large variations of $Q_{S}$ particularly over the central Bay of Bengal (Fig. 13a) and the eastern equatorial Indian Ocean (Fig. 13b, c). Similar to the Pacific Ocean and the Atlantic Oceans, all the products underestimated the variability over Indian Ocean with SD values lower by $6-10 \mathrm{Wm}^{-2}$ in the individual products. $Q_{S}$ variability in the TropFlux is more closely aligned with the observation but has the large bias $\left(-9 \mathrm{Wm}^{-2}\right)$ and least RMSE (Fig. 13, Table 4). CM performance lies in between CORE-II and TropFlux. All the products show 
large deviations in daily $Q_{L}$ variations over the central Bay of Bengal (Fig. 14a). $Q_{\perp}$ has high values ranging up to 450 $\mathrm{Wm}^{-2}$ in the Indian Ocean during summer monsoon. None of the buoy locations in PIRATA or TRITON has shown this high $Q_{L}$ values (Fig. 8, Fig. 11). CORE-II and TropFlux overestimated the observed variability in the Indian Ocean. CM has better $Q_{L}$ estimations compared to CORE-II and TropFlux, and also has least RMSE, highest CC and SD values close to RAMA observations. In summary, $Q_{S}$ in TropFlux has better performance in terms of least RMSE and highest CC but $Q_{\perp}$ in CM outplayed all other products.

Apart from the time series variations, we also show the seasonal spatial mean and variability in all the products. $Q_{S}$ shows large values over the subtropical region in all seasons and is mainly due to the presence of low cloudiness over this region. Except the south pacific convergence zone (SPCZ) and the western equatorial Indian Ocean, the entire southern hemisphere receives uniform $Q_{S}$ with an average between 300 and $340 \mathrm{Wm}^{-2}$ range in the winter. These values are lower than $300 \mathrm{Wm}^{-2}$ (Fig. 2) in the equatorial Pacific and the Atlantic Oceans. All the products show similar mean spatial distribution pattern over most of the domain. However, TropFlux shows low $Q_{S}$ values over the northern Pacific and the Atlantic Oceans compared to CM and CORE-II. But, the daily variability is less in CORE-II as compared to other two products (Fig. 3). Equatorial region shows large $Q_{S}$ in the spring and summer. But, these values are low $\left(200-220 \mathrm{Wm}^{-2}\right)$ in the northern ITCZ, west coast of the North America and in the SPCZ during the same time. $Q_{S}$ values over west coast of the South America and the Africa show lower values in the summer as compared to the adjacent regions of the same latitudes. This is due to the presence of large cloud amounts $(\sim 80 \%)$ over these regions. The Indian Ocean shows low $Q_{S}$ compared to the Pacific and the Atlantic during summer and mainly due to persistent cloud cover during the Indian Summer Monsoon. CM shows highest mean values in all seasons, followed by CORE-II. The regions with low $Q_{S}$ values show more variability with high SD values (Fig. 3). $Q_{L}$ in the tropical oceans shows seasonal spatial pattern determined by ITCZ positions and does not change significantly over the Pacific and the Atlantic Oceans. But, $Q_{L}$ in the Indian Ocean has intraseasonal variability determined by the features like monsoons, MJO and enhanced intraseasonal convection. Thus, $Q_{\perp}$ in the Indian Ocean shows highest value during summer as compared to the Pacific and Atlantic Oceans and is mainly due to the presence of deep clouds [76]. Hence, spatial pattern of $Q_{L}$ over Indian Ocean changes with the summer and winter monsoon (Fig. 4). Opposite to $Q_{S}$, large $Q_{L}$ values in the Indian Ocean are associated with the least $Q_{L}$ variability (Fig. 5).

The SST variability is mainly determined by the net heat flux on seasonal and ISO time scale over the north Indian
Ocean and in the western Pacific Ocean [47, 98]. Errors associated with the $Q_{\mathrm{S}}$ and $Q_{\mathrm{L}}$ will affect the net heat flux computation and hence the SST. Assuming net heat fluxes are solely responsible for the SST change and using heat budget equation, we estimated the errors in SST associated with the $Q_{S}$ and $Q_{L}$ errors. The assumption is that, the maximum possible errors involved in SST tendency due to RMSE in $Q_{S}$ and $Q_{L}$. Four representative locations, i.e., $0^{\circ} \mathrm{N}, 80.5^{\circ} \mathrm{E}$ in Indian Ocean, $0^{\circ} \mathrm{N}, 23^{\circ} \mathrm{W}$ in the central Atlantic Ocean and $0^{\circ} \mathrm{N}, 110^{\circ} \mathrm{W}$ (east) and $0^{\circ} \mathrm{N}, 165^{\circ} \mathrm{E}$ (west), in the Pacific Ocean are used in this study. We computed the monthly RMSE error for all the products and estimated the MLD using temperature profiles for all corresponding locations (Table 5). Monthly SST error can be as large as $0.2-0.3(0.1-0.2){ }^{\circ} \mathrm{C}$ associated with error in $Q_{S}\left(Q_{L}\right)$. These results stress the need to improve the radiative flux data products in the tropics with better reanalysis methods and algorithms. Furthermore, these results also emphasize the necessity to produce enhanced, alternative and more accurate flux products. On the other hand, radiative fluxes from satellite products like $C M$ have better agreement with the observations. Both $Q_{S}$ and $Q_{L}$ from $C M$ can be used as an alternative to the existing reanalysis products in all the tropical oceans. In the present study, the $Q_{S}$ from TropFlux shows better CC values than CM compared with observations. But, caution is that the TropFlux is developed and corrected using ISCCP and GTMBA observations, respectively. But the ISCCP data are not available from 2009 and the TropFlux developed using other alternative methods like using OLR could enhance the errors in the OGCMs. Furthermore, $Q_{S}$ from $C M$ also closely follows the TropFlux data in all three tropical oceans. Thus, given the best CC values in $Q_{L}$ from $C M$ in all the three tropical oceans and considering its real-time availability, radiative fluxes from $\mathrm{CM}$ can be used as an alternative to the fluxes from reanalysis and hybrid products.

Acknowledgements We greatly acknowledge the Open access funding provided by Uppsala University. The research described in this paper was begun while the first author was at INCOIS. This research work was supported by INCOIS, and authors are thankful to Director, INCOIS, Ministry of Earth Sciences (MoES) for providing the necessary facilities. Authors also thank Dr. Ravichandran, Director, National Centre for Polar and Ocean Research (NCPOR); Prof. Anna Rutgersson, Department of Earth Sciences, Uppsala University and the program for air, water and landscape theory (LUVAL), Department of Earth Sciences, Uppsala University for their support to complete this work. TropFlux data are accessed from INCOIS data server. The CERES/MODIS $Q_{S}$ and $Q_{\perp}$ data are downloaded from https://ceres -tool.larc.nasa.gov/ord-tool/jsp/SYN1 degSelection.jsp. The CORE-II data are downloaded from http://data1.gfdl.noaa.gov/nomads/ forms/core/COREv2/CIAF_v2.html. We are grateful to GTMBA program and MODIS, GFDL for providing the CM and CORE-II datasets. Finally, we thank the anonymous reviewers whose valuable comments improved the manuscript substantially. This is also INCOIS Contribution number 350 . 


\section{Compliance with ethical standards}

Conflict of interest The authors declare that they have no conflict of interest.

Open Access This article is distributed under the terms of the Creative Commons Attribution 4.0 International License (http://creativeco mmons.org/licenses/by/4.0/), which permits unrestricted use, distribution, and reproduction in any medium, provided you give appropriate credit to the original author(s) and the source, provide a link to the Creative Commons license, and indicate if changes were made.

\section{References}

1. Achuthavarier D, Krishnamurthy V, Kirtman BP, Huang B (2012) Role of the Indian Ocean in the ENSO-Indian summer monsoon teleconnection in the NCEP climate forecast system. J Clim 25(7):2490-2508

2. Adam O, Bischoff T, Schneider T (2016) Seasonal and interannual variations of the energy flux equator and ITCZ. Part I: zonally averaged ITCZ position. J Clim 29(9):3219-3230

3. Alexander MA, Bladé I, Newman M, Lanzante JR, Lau NC, Scott JD (2002) The atmospheric bridge: the influence of ENSO teleconnections on air-sea interaction over the global Oceans. J Clim 15(16):2205-2231

4. Barkstrom BR (1999) Ceres: the start of the next generation of radiation measurements. Adv Space Res 24(7):907-914

5. Barkstrom BR, Smith GL (1986) The earth radiation budget experiment: science and implementation. Rev Geophys 24(2):379-390

6. Barkstrom B, Harrison E, Smith G, Green R, Kibler J, Cess R, ERBE Science Team (1989) Earth radiation budget experiment (ERBE) archival and April 1985 results. Bull Am Meteor Soc 70(10):1254-1262

7. Boschat G, Terray P, Masson S (2011) Interannual relationships between Indian Summer Monsoon and Indo-Pacific coupled modes of variability during recent decades. Clim Dyn 37(5-6):1019-1043

8. Bourlès $B$, Lumpkin R, McPhaden MJ, Hernandez F, Nobre P, Campos E, Servain J (2008) The PIRATA program: history, accomplishments, and future directions. Bull Am Meteor Soc 89(8):1111-1125

9. Brodeau L, Barnier B, Treguier AM, Penduff T, Gulev S (2010) An ERA40-based atmospheric forcing for global ocean circulation models. Ocean Model 31(3-4):88-104

10. Cassou C (2008) Intraseasonal interaction between the Madden-Julian oscillation and the North Atlantic Oscillation. Nature 455(7212):523

11. Charney JG, Shukla J (1981) Predictability of monsoons. In: Lighthill J, Pearce RP (eds) Monsoon dynamics

12. Chaudhuri AH, Ponte RM, Forget G, Heimbach P (2013) A comparison of atmospheric reanalysis surface products over the Ocean and implications for uncertainties in air-sea boundary forcing. J Clim 26(1):153-170

13. Chongyin L, Ruijin H, Hui $Y$ (2005) Intraseasonal oscillation in the tropical Indian Ocean. Adv Atmos Sci 22(5):617-624

14. Chowdary JS, Parekh A, Ojha S, Gnanaseelan C (2015) Role of upper Ocean processes in the seasonal SST evolution over tropical Indian Ocean in climate forecasting system. Clim Dyn 45(9-10):2387-2405

15. Clayson CA, Weitlich D (2007) Variability of tropical diurnal sea surface temperature. J Clim 20(2):334-352
16. Curry JA, Bentamy A, Bourassa MA, Bourras D, Bradley EF, Brunke M, Eymard L (2004) Seaflux. Bull Am Meteor Soc 85(3):409-424

17. Du Y, Qu T, Meyers G, Masumoto Y, Sasaki H (2005) Seasonal heat budget in the mixed layer of the southeastern tropical Indian Ocean in a high-resolution ocean general circulation model. J Geophys Res Oceans. https://doi.org/10.1029/2004J C002845

18. Duvel JP, Bellenger H, Xavier P, Doblas-Reyer F (2008). Air-sea processes in the Indian Ocean and the intraseasonal oscillation. In: Proceedings ECMWF workshop on Atmosphere-Ocean interaction, pp 83-92

19. Fairall CW, Bradley EF, Rogers DP et al (1996) Bulk parameterization of air-sea fluxes for Tropical Ocean-Global Atmosphere Coupled-Ocean Atmosphere Response Experiment. J Geophys Res Ocean 101:3747-3764. https://doi.org/10.1029/95JC03205

20. Feng L, Lin A, Wang L, Qin W, Gong W (2018) Evaluation of sunshine-based models for predicting diffuse solar radiation in China. Renew Sustain Energy Rev 94:168-182

21. Feng L, Qin W, Wang L, Lin A, Zhang M (2018) Comparison of artificial intelligence and physical models for forecasting photosynthetically-active radiation. Remote Sens 10(11):1855

22. Foltz GR, Evan AT, Freitag HP, Brown S, McPhaden MJ (2013) Dust accumulation biases in PIRATA shortwave radiation records. J Atmos Ocean Technol 30(7):1414-1432

23. Freitag HP, McCarty ME, Nosse C, Lukas R, McPhaden MJ, Cronin MF (1999) COARE Seacat data: calibrations and quality control procedures. NOAA Tech Memo ERL PMEL 115:89

24. Freitag HP, O'Haleck M, Thomas GC, McPhaden MJ (2001) Calibration procedures and instrumental accuracies for ATLAS wind measurements. NOAA Tech Memo OAR PMEL 119:20

25. Fu C, Diaz HF, Fletcher JO (1986) Characteristics of the response of sea surface temperature in the central Pacific associated with warm episodes of the Southern Oscillation. Mon Weather Rev 114(9):1716-1739

26. Gadgil S, Rajeevan M, Nanjundiah R (2005) Monsoon prediction-why yet another failure. Curr Sci 88(9):1389-1400

27. Gadgil S, Vinayachandran PN, Francis PA (2003) Droughts of the Indian summer monsoon: role of clouds over the Indian Ocean. Curr Sci 154:1713-1719

28. Goswami BN (2005) South Asian monsoon. In: Intraseasonal variability in the atmosphere-ocean climate system. Springer, Berlin, pp 19-61

29. Griffies SM, Biastoch A, Böning C, Bryan F, Danabasoglu G, Chassignet EP, Hazeleger W (2009) Coordinated ocean-ice reference experiments (COREs). Ocean Model 26(1-2):1-46

30. Griffiths ML, Kimbrough AK, Gagan MK, Drysdale RN, Cole JE, Johnson KR, Hantoro WS (2016) Western Pacific hydroclimate linked to global climate variability over the past two millennia. Nat Commun 7:11719

31. Harrison EF, Minnis P, Barkstrom BR et al (1990) Seasonal variation of cloud radiative forcing derived from the earth radiation budget experiment. J Geophys Res 95:18687-18703. https://doi.org/10.1029/JD095iD11 1 18687

32. Hatzianastassiou N, Matsoukas C, Fotiadi A, Pavlakis KG Drakakis E, Hatzidimitriou D, Vardavas I (2005) Global distribution of Earth's surface shortwave radiation budget. Atmos Chem Phys 5(10):2847-2867

33. Hendon $\mathrm{HH}$ (2003) Indonesian rainfall variability: impacts of ENSO and local air-sea interaction. J Clim 16(11):1775-1790

34. Hendon HH, Glick J (1997) Intraseasonal air-sea interaction in the tropical Indian and Pacific Oceans. J Clim 10(4):647-661

35. Jayakumar A, Vialard J, Lengaigne $M$ et al (2011) Processes controlling the surface temperature signature of the Madden-Julian Oscillation in the thermocline ridge of the Indian 
Ocean. ClimDyn 37:2217-2234. https://doi.org/10.1007/ s00382-010-0953-5

36. Jin FF, An SI (1999) Thermocline and zonal advective feedbacks within the equatorial ocean recharge oscillator model for ENSO. Geophys Res Lett 26(19):2989-2992

37. Kanamitsu M, Ebisuzaki W, Woollen J, Yang SK, Hnilo JJ, Fiorino M, Potter GL (2002) Ncep-doe amip-ii reanalysis ( $r-2$ ). Bull Am Meteor Soc 83(11):1631-1643

38. Kang I-S, An S-I, Jin F-F (2001) A systematic approximation of the SST anomaly equation for ENSO. J Meteorol Soc Jpn 79:1-10. https://doi.org/10.2151/jmsj.79.1

39. Kang IS, Jin K, Wang B et al (2002) Intercomparison of the climatological variations of Asian summer monsoon precipitation simulated by 10 GCMs. ClimDyn 19:383-395. https:// doi.org/10.1007/s00382-002-0245-9

40. Kapsch M-L, Graversen RG, Tjernström M et al (2016) The effect of downwelling longwave and shortwave radiation on arctic summer sea ice. J Clim 29:1143-1159. https://doi. org/10.1175/JCLI-D-15-0238.1

41. Kara AB, Rochford PA, Hurlburt HE (2000) An optimal definition for Ocean mixed layer depth. J Geophys Res Ocean 105:16803-16821. https://doi.org/10.1029/2000JC900072

42. Kato S, Loeb NG, Rose FG et al (2013) Surface irradiances consistent with CERES-derived top-of-atmosphere shortwave and longwave irradiances. J Clim 26:2719-2740. https://doi. org/10.1175/JCLI-D-12-00436.1

43. Kato S, Loeb NG, Rutan DA, Rose FG (2015) Clouds and the Earth's Radiant Energy System (CERES) data products for climate research. J Meteorol Soc Jpn Ser II 93(6):597-612

44. Kim W, Cai W (2013) Second peak in the far eastern Pacific sea surface temperature anomaly following strong EI Niño events. Geophys Res Lett 40:4751-4755. https://doi. org/10.1002/grl.50697

45. Kirtman B, Vecchi GA (2011) Why climate modelers should worry about atmospheric and oceanic weather. In: The Global monsoon system: research and forecast, pp 511-523

46. Kirtman B, Power SB, Adedoyin AJ, Boer GJ, Bojariu R, CamilIoni I, Doblas-Reyes F, Fiore AM et al (2013) Chapter 11 - Nearterm climate change: projections and predictability. In: Climate change 2013: the physical science basis. IPCC working group I contribution to AR5. Eds. IPCC. Cambridge University Press, Cambridge

47. Klein SA, Soden BJ, Lau NC (1999) Remote sea surface temperature variations during ENSO: evidence for a tropical atmospheric bridge. J Clim 12(4):917-932

48. Koberle C, Philander SGH (1994) On the processes that control seasonal variations of sea surface temperatures in the tropical Pacific Ocean. Tellus A 46:481-496. https://doi.org/10.103 4/j.1600-0870.1994.00011.x

49. Krishnamurthy V, Kirtman BP (2003) Variability of the Indian Ocean: relation to monsoon and ENSO. Q J R Meteorol Soc 129:1623-1646. https://doi.org/10.1256/qj.01.166

50. Kumar BP, Vialard J, Lengaigne $M$ et al (2012) TropFlux: air-sea fluxes for the global tropical Oceans-description and evaluation. ClimDyn 38:1521-1543. https://doi.org/10.1007/s0038 2-011-1115-0

51. Lake BJ, Noor SM, Freitag HP, McPhaden MJ (2003) Calibration procedures and instrumental accuracy estimates of ATLAS air temperature and relative humidity measurements. NOAA Tech Memo OAR PMEL 123:23

52. Large WG, Yeager SG (2009) The global climatology of an interannually varying air-sea flux data set. ClimDyn 33:341-364. https://doi.org/10.1007/s00382-008-0441-3

53. Large WG, Yeager SG (2004) Diurnal to decadal global forcing for Ocean and sea-ice models: the data sets and flux climatologies. NCAR Technical Note NCAR/TN-460+STR. https ://doi.org/10.5065/D6KK98Q6

54. Lau NC, Nath MJ (1996) The role of the "atmospheric bridge" in linking tropical pacific ENSO events to extratropical SST anomalies. J Clim 9:2036-2057

55. Lau KM, Kim MK, Kim KM (2006) Asian summer monsoon anomalies induced by aerosol direct forcing: the role of the Tibetan Plateau. Clim Dyn 26(7-8):855-864

56. Lau NC, Nath MJ (2000) Impact of ENSO on the variability of the Asian-Australian monsoons as simulated in GCM experiments. J Clim 13(24):4287-4309

57. Lau NC, Nath MJ (2003) Atmosphere-Ocean variations in the Indo-Pacific sector during ENSO episodes. J Clim 16(1):3-20

58. Lind RJ, Katsaros KB (1986) Radiation measurements and model results from R/V Oceanographer during STREX 1980. J Geophys Res Atmos 91(D12):13308-13314

59. Ma Z, Fei J, Huang X et al (2015) Contributions of surface sensible heat fluxes to tropical cyclone. Part I: evolution of tropical cyclone intensity and structure. J Atmos Sci 72:120-140. https ://doi.org/10.1175/JAS-D-14-0199.1

60. Ma Y, Pinker RT (2012) Shortwave radiative fluxes from satellites: an update. J Geophys Res Atmos. https://doi.org/10.1029/2012j d018332

61. McPhaden MJ, Busalacchi AJ, Anderson DLT (2010) A toga retrospective. Oceanography 23:86-103. https://doi.org/10.5670/ Oceanog.2010.26

62. McPhaden MJ, Busalacchi AJ, Cheney R et al (1998) The Tropical Ocean-Global Atmosphere observing system: a decade of progress. J Geophys Res Ocean 103:14169-14240. https://doi. org/10.1029/97JC02906

63. McPhaden MJ, Meyers G, Ando K et al (2009) RAMA: the research moored array for African-Asian-Australian monsoon analysis and prediction. Bull Am MeteorolSoc 90:459-480. https://doi.org/10.1175/2008BAMS2608.1

64. McWilliams JC (1996) Modeling the Oceanic general circulation. Annu Rev Fluid Mech 28(1):215-248

65. Medovaya M (2002) Assessing Ocean buoy shortwave observations using clear-sky model calculations. J Geophys Res 107:3014. https://doi.org/10.1029/2000JC000558

66. Murtugudde R, McCreary JP, Busalacchi AJ (2000) Oceanic processes associated with anomalous events in the Indian Ocean with relevance to 1997-1998. J Geophys Res Ocean 105:3295-3306. https://doi.org/10.1029/1999JC900294

67. Parekh A, Gnanaseelan C, Jayakumar A (2011) Impact of improved momentum transfer coefficients on the dynamics and thermodynamics of the north Indian Ocean. J Geophys Res 116:C01004. https://doi.org/10.1029/2010JC006346

68. Pavlakis KG, Hatzianastassiou N, Matsoukas C, Fotiadi A, Vardavas I (2008) ENSO surface shortwave radiation forcing over the tropical Pacific. Atmos Chem Phys 8(18):5565-5577

69. Payne RE, Huang K, Weller RA, Freitag HP, Cronin MF (2002) A comparison of buoy meteorological systems (No. WHOI2002-10). Woods hole oceanographic institution MA

70. Pinker RT, Bentamy A, Katsaros KB et al (2014) Estimates of net heat fluxes over the Atlantic Ocean. J Geophys Res Ocean 119:410-427. https://doi.org/10.1002/2013JC009386

71. Pinker RT, Wang H, Grodsky SA (2009) How good are ocean buoy observations of radiative fluxes? GRL 36:L10811

72. Pinker RT, Bentamy A, Zhang B, Chen W, Ma Y (2017) The net energy budget at the ocean-atmosphere interface of the "Cold Tongue" region. J Geophys Res Oceans. https://doi. org/10.1002/2016JC012581

73. Pinker RT, Bentamy A, Katsaros KB, Ma Y, Li C (2014) Estimates of net heat fluxes over the Atlantic Ocean. J Geophys Res Oceans. https://doi.org/10.1002/2013JC009386 
74. Pinker RT, Grodsky SA, Zhang B, Busalacchi A, Chen W (2017) ENSO impact on surface radiative fluxes as observed from space. J Geophys Res Oceans 122(10):7880-7896

75. Pinker RT, Zhang BZ, Weller RA, Chen W (2018) Evaluating surface radiation fluxes observed from satellites in the southeastern Pacific Ocean. Geophys Res Lett. https://doi. org/10.1002/2017GL076805

76. Pokhrel S, Hazra A, Saha SK et al (2018) Contrast in monsoon precipitation over Oceanic region of north Bay of Bengal and east equatorial Indian Ocean. Int J Climatol. https://doi. org/10.1002/joc.5433

77. Praveen Kumar B, Vialard J, Lengaigne M et al (2013) TropFlux wind stresses over the tropical Oceans: evaluation and comparison with other products. ClimDyn 40:2049-2071. https ://doi.org/10.1007/s00382-012-1455-4

78. Qin W, Wang L, Lin A, Zhang M, Xia X, Hu B, Niu Z (2018) Comparison of deterministic and data-driven models for solar radiation estimation in China. Renew Sustain Energy Rev 81:579-594

79. Qiu J (2003) Broadband extinction method to determine aerosol optical depth from accumulated direct solar radiation. J Appl Meteorol 42(11):1611-1625

80. Qu T (2003) Mixed layer heat balance in the western North Pacific. J Geophys Res Oceans. https://doi.org/10.1029/2002J C001536

81. Rahaman H, Ravichandran M (2013) Evaluation of nearsurface air temperature and specific humidity from hybrid global products and their impact on latent heat flux in the North Indian Ocean. J Geophys Res Ocean 118:1034-1047. https://doi.org/10.1002/jgrc.20085

82. Ramanathan V, Cess RD, Harrison EF et al (1989) Cloudradiative forcing and climate: results from the earth radiation budget experiment. Science 80(243):57-63. https://doi. org/10.1126/science.243.4887.57

83. Ramesh Kumar MR, Pinker RT, Mathew S, Venkatesan R, Chen W (2017) Evaluation of radiative fluxes over the north Indian Ocean. J Theor Climatol. https://doi.org/10.1007/s0070 4-017-2141-6

84. Randall DA, Wood RA, Bony S, Colman R, Fichefet T, Fyfe J, Stouffer RJ (2007) Climate models and their evaluation. In: Climate change 2007: the physical science basis. Contribution of working group I to the fourth assessment report of the IPCC (FAR), pp. 589-662. Cambridge University Press

85. Rao RR, Jitendra V, GirishKumar MS, Ravichandran M, Ramakrishna SSVS (2015) Interannual variability of the Arabian Sea Warm Pool: observations and governing mechanisms. Clim Dyn 44:2119-2136. https://doi.org/10.1007/s0038 2-014-2243-0

86. Raschke E, Ohmura A, Rossow WB et al (2005) Cloud effects on the radiation budget based on ISCCP data (1991 to 1995). Int J Climatol 25:1103-1125. https://doi.org/10.1002/joc.1157

87. Raymond DJ, Bretherton Christopher S, Molinari J (2006) Dynamics of the intertropical convergence zone of the East Pacific. J AtmosSci 63:582-597. https://doi.org/10.1175/ JAS3642.1

88. Roesch A, Wild M, Pinker R, Ohmura A (2002) Comparison of spectral surface albedos and their impact on the general circulation model simulated surface climate. J Geophys Res Atmos 107(D14):ACL-13

89. Romatschke U, Medina S, Houze RA (2010) Regional, seasonal, and diurnal variations of extreme convection in the South Asian region. J Clim 23:419-439. https://doi. org/10.1175/2009JCLI3140.1

90. Rossow WB, Schiffer RA (1999) Advances in understanding clouds from ISCCP. Bull Am Meteor Soc 80(11):2261-2287
91. Rutan DA, Kato S, Doelling DR et al (2015) CERES synoptic product: methodology and validation of surface radiant flux. J Atmos Ocean Technol 32:1121-1143. https://doi. org/10.1175/JTECH-D-14-00165.1

92. Saji NH, Goswami BN, Vinayachandran PN, Yamagata T (1999) A dipole mode in the tropical Indian Ocean. Nature 401:360363. https://doi.org/10.1038/43854

93. Schiffer RA, Rossow WB (1983) The International Satellite Cloud Climatology Project (ISCCP)-The first project of the world climate research programme. Bull Am MeteorolSoc 64:779-784. https://doi.org/10.1175/15200477(1991)072\%3c0002:ICDP\%3e2.0.CO;2

94. Schott FA, McCreary JP (2001) The monsoon circulation of the Indian Ocean. ProgOceanogr 51:1-123. https://doi. org/10.1016/S0079-6611(01)00083-0

95. Schott FA, Xie S-P, McCreary JP (2009) Indian Ocean circulation and climate variability. Rev Geophys 47:RG1002. https ://doi.org/10.1029/2007rg000245

96. Schott FA, Xie S-P, McCreary JP Jr (2009) Indian Ocean circulation and climate variability. Rev Geophys 47:1-46. https://doi. org/10.1029/2007RG000245.1.INTRODUCTION

97. Sengupta D, Goswami BN, Senan R (2001) Coherent intraseasonal oscillations of Ocean and atmosphere during the Asian summer monsoon. Geophys Res Lett 28:4127-4130. https:// doi.org/10.1029/2001GL013587

98. Sengupta D, Ravichandran M (2001) Oscillations of bay of Bengal sea surface temperature during the 1998 summer monsoon. Geophys Res Lett 28:2033-2036. https://doi. org/10.1029/2000GL012548

99. Shahi NR, Thapliyal PK, Sharma R, Pal PK, Sarkar A (2011) Estimation of net surface shortwave radiation over the tropical Indian Ocean using geostationary satellite observations: algorithm and validation. J Geophys Res Oceans. https://doi. org/10.1029/2011JC007105

100. Shukla J (1998) Predictability in the Midst of Chaos: a scientific basis for climate forecasting. Science 80(282):728-731. https:// doi.org/10.1126/science.282.5389.728

101. Smith GL, Priestley KJ, Loeb NG et al (2011) Clouds and Earth Radiant Energy System (CERES), a review: past, present and future. AdvSp Res 48:254-263. https://doi.org/10.1016/j. asr.2011.03.009

102. Smith SR, Legler DM, Verzone KV (2001) Quantifying uncertainties in NCEP reanalyses using high-quality research vessel observations. J Clim 14(20):4062-4072

103. Sobel AH, Maloney ED, Bellon G, Frierson DM (2008) The role of surface heat fluxes in tropical intraseasonal oscillations. Nat Geosci 1:653-657. https://doi.org/10.1038/ngeo312

104. Tian B, Ramanathan V (2002) Role of tropical clouds in surface and atmospheric energy budget. J Clim 15(3):296-305

105. Tomaziello ACN, Carvalho LM, Gandu AW (2016) Intraseasonal variability of the Atlantic Intertropical Convergence Zone during austral summer and winter. Clim Dyn 47(5-6):1717-1733

106. Trenberth KE, Branstator GW, Karoly D et al (1998) Progress during TOGA in understanding and modeling global teleconnections associated with tropical sea surface temperatures. J Geophys Res Ocean 103:14291-14324. https://doi. org/10.1029/97JC01444

107. Trenberth KE, Stepaniak DP (2004) The flow of energy through the earth's climate system. Q J R MeteorolSoc 130:2677-2701. https://doi.org/10.1256/qj.04.83

108. Trolliet $M$, Walawender JP, Bourlès $B$, Boilley $A$, Trentmann $J$, Blanc $P$, Lefèvre $M$, Wald L (2017) Estimating downwelling solar irradiance at the surface of the tropical Atlantic Ocean: a comparison of PIRATA measurements against several 
re-analyses and satellite-derived data sets. Ocean Sci. Discuss. https://doi.org/10.5194/os-2017-95 (in review)

109. Tsujino H, Urakawa S, Nakano H, Small RJ, Kim WM, Yeager SG, Böning CW (2018) JRA-55 based surface dataset for driving ocean-sea-ice models (JRA55-do). Ocean Model 130:79-139

110. Venugopal T, Rahaman $H$, Ravichandran M, Ramakrishna SSVS (2016) Evaluation of MODIS/CERES downwelling shortwave and longwave radiation over global tropical oceans. In: Proceedings SPIE 9876, remote sensing of the atmosphere, clouds, and precipitation VI, 98761F (9 May 2016)

111. Vialard J, Foltz GR, McPhaden MJ et al (2008) Strong Indian Ocean sea surface temperature signals associated with the Madden-Julian Oscillation in late 2007 and early 2008. Geophys Res Lett 35:L19608. https://doi.org/10.1029/2008G L035238

112. Vialard J, Menkes C, Boulanger JP, Delecluse P, Guilyardi E, McPhaden MJ, Madec G (2001) A model study of Oceanic mechanisms affecting equatorial Pacific sea surface temperature during the 1997-98 El Niño. J Phys Oceanogr 31(7):1649-1675

113. Vimont DJ, Kossin JP (2007) The Atlantic Meridional Mode and hurricane activity. Geophys Res Lett 34:L07709. https:// doi.org/10.1029/2007GL029683

114. Wang B, Zhang Q (2002) Pacific-East Asian teleconnection. Part II: how the Philippine Sea anomalous anticyclone is established during El Niño development. J Clim 15:32523265. https://doi.org/10.1175/1520-0442(2002)015\%3c325 2:PEATPI\%3e2.0.CO;2

115. Wang C, Enfield DB (2001) The tropical western hemisphere warm pool. Geophys Res Lett 28:1635-1638. https://doi. org/10.1029/2000GL011763

116. Wang C, Magnusdottir G (2006) The ITCZ in the Central and Eastern Pacific on synoptic time scales. Mon Weather Rev 134:1405-1421. https://doi.org/10.1175/MWR3130.1

117. Wang W, McPhaden MJ, Wang W, McPhaden MJ (1999) The surface-layer heat balance in the equatorial Pacific Ocean. Part I: mean seasonal cycle*. J Phys Oceanogr 29:1812-1831. https://doi.org/10.1175/1520-0485(1999)029\%3c1812:TSLHB I\%3e2.0.CO;2

118. Wang B, Wu R, LiT (2003) Atmosphere-warm Ocean interaction and its impacts on Asian-Australian monsoon variation. J Clim 16(8):1195-1211

119. Wang L, Lu Y, Zou L, Feng L, Wei J, Qin W, Niu Z (2019) Prediction of diffuse solar radiation based on multiple variables in China. Renew Sustain Energy Rev 103:151-216

120. Webster PJ, Magana VO, Palmer TN, Shukla J, Tomas RA, Yanai MU, Yasunari T (1998) Monsoons: processes, predictability, and the prospects for prediction. J Geophys Res Oceans 103(C7):14451-14510

121. Webster PJ, Moore AM, Loschnigg JP, Leben RR (1999) Coupled Ocean-atmosphere dynamics in the Indian Ocean during 1997-98. Nature 401(6751):356
122. Wielicki BA, Barkstrom BR, Baum BA et al (1998) Clouds and the earth's radiant energy system (CERES): algorithm overview. IEEE Trans Geosci Remote Sens 36:1127-1141. https:// doi.org/10.1109/36.701020

123. Wielicki BA, Barkstrom BR, Harrison EF, Lee RB III, Louis Smith G, Cooper JE (1996) Clouds and the Earth's Radiant Energy System (CERES): an earth observing system experiment. Bull Am Meteor Soc 77(5):853-868

124. Wilber AC, Smith GL, Gupta SK, Stackhouse PW (2006) Annual cycles of surface shortwave radiative fluxes. J Clim 19(4):535-547

125. Wu R, Kirtman BP (2005) Roles of Indian and Pacific Ocean air-sea coupling in tropical atmospheric variability. Clim Dyn 25(2-3):155-170

126. Xie S-P, Philander SGH (1994) A coupled Ocean-atmosphere model of relevance to the ITCZ in the eastern Pacific. Tellus $A$ 46:340-350. https://doi.org/10.1034/j.1600-0870.1994.t01-100001.x

127. Yan H, Huang J, Minnis P et al (2011) Comparison of CERES surface radiation fluxes with surface observations over Loess Plateau. Remote Sens Environ 115:1489-1500. https://doi. org/10.1016/j.rse.2011.02.008

128. Yu L, Jin X, Weller RA (2008) Multidecade Global Flux Datasets from the Objectively Analyzed Air-sea Fluxes (OAFlux) Project: latent and sensible heat fluxes, ocean evaporation, and related surface meteorological variables. OAFlux Project Technical Report. OA-2008-01

129. Zhang Y, Rossow WB, Lacis AA et al (2004) Calculation of radiative fluxes from the surface to top of atmosphere based on ISCCP and other global data sets: refinements of the radiative transfer model and the input data. J Geophys Res D: Atmos 109:1-27. https://doi.org/10.1029/2003JD004457

130. Zhou L-T (2013) Influence of thermal state of warm pool in western Pacific on sensible heat flux. AtmosSci Lett 14:91-96. https://doi.org/10.1002/asl2.422

131. Ziemiański M, Grabowski WW, Moncrieff MW (2005) Explicit convection over the western Pacific warm pool in the Community Atmospheric Model. J Clim 18(10):1482-1502

132. Zou L, Wang L, Li J, Lu Y, Gong W, Niu Y (2019) Global surface solar radiation and photovoltaic power from coupled model intercomparison project phase 5 climate models. J Clean Prod 224:304-324

133. Zuidema P (2003) Convective clouds over the Bay of Bengal. Mon Weather Rev 131:780-798

Publisher's Note Springer Nature remains neutral with regard to jurisdictional claims in published maps and institutional affiliations. 